Portland State University

PDXScholar

1989

\title{
Frequency responses of hearing aids coupled with FM auditory trainers
}

Robert Bruce Morrison

Portland State University

Follow this and additional works at: https://pdxscholar.library.pdx.edu/open_access_etds

Part of the Speech Pathology and Audiology Commons Let us know how access to this document benefits you.

\section{Recommended Citation}

Morrison, Robert Bruce, "Frequency responses of hearing aids coupled with FM auditory trainers" (1989). Dissertations and Theses. Paper 3913.

https://doi.org/10.15760/etd.5797

This Thesis is brought to you for free and open access. It has been accepted for inclusion in Dissertations and Theses by an authorized administrator of PDXScholar. Please contact us if we can make this document more accessible: pdxscholar@pdx.edu. 
AN ABSTRACT OF THE THESIS OF Robert Bruce Morrison for the Master of Science in Speech Communication presented May 4, 1989.

Title: Frequency Responses of Hearing Aids Coupled with FM Auditory Trainers.

APPROVED BY MEMBERS OF THE THESIS COMMITTEE:

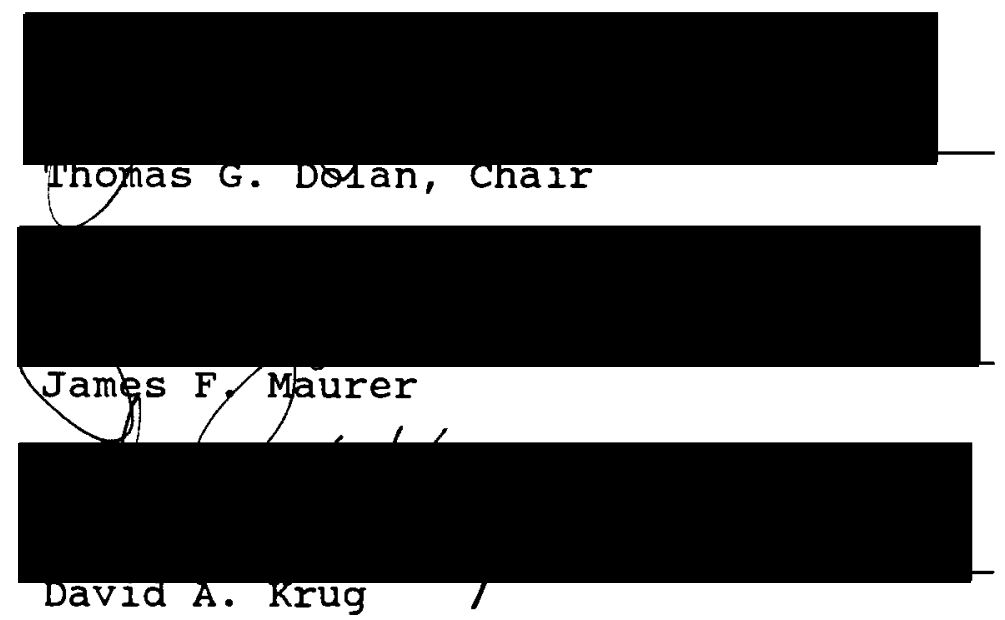

This study examined the frequency response characteristics of three behind-the-ear hearing aids alone and in combination with three FM auditory trainers. The hearing aids and FM auditory trainers were coupled using two different methods: direct audio input and personal miniloop. Also, two different gain control settings were used. Frequency responses were evaluated using a template method specified in ANSI S3.22 1982 standards. A larger percentage 
of the personal mini-loop combinations failed to meet this ANSI standard as compared to the direct audio input combinations ( $72.3 \%$ vs. 50\%). The frequency response curves for various combinations of hearing aids and FM auditory trainers were also separated into high and low frequency bands. Significant changes in output were found for the low frequency region, and these changes were dependent upon the coupling method. Specifically, the personal mini-loop tended to produce a significant reduction in output in the low frequency band as compared to that of the hearing aid alone. The use of direct audio input resulted in a significant increase in output in the low frequency band as compared to that of the hearing aid alone. This latter method produced the best overall agreement with the hearing aid frequency response, especially when the FM auditory trainer was set at full on gain and the hearing aid at a low gain setting. 
FREQUENCY RESPONSES OF HEARING AIDS COUPLED WITH FM AUDITORY TRAINERS

by

ROBERT BRUCE MORRISON

A thesis submitted in partial fulfillment of the requirements for the degree of

\author{
MASTER OF SCIENCE \\ in \\ SPEECH COMMUNICATION \\ with emphasis in Audiology
}

Portland State University

1989 
TO THE OFFICE OF GRADUATE STUDIES:

The members of the Committee approve the thesis of Robert Bruce Morrison presented May 4, 1989.

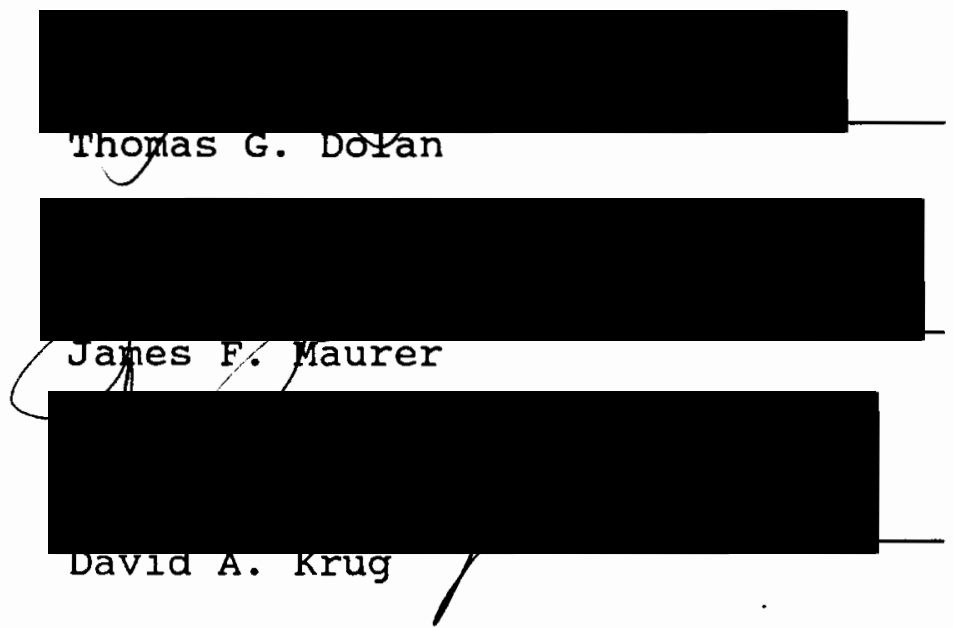

APPROVED :

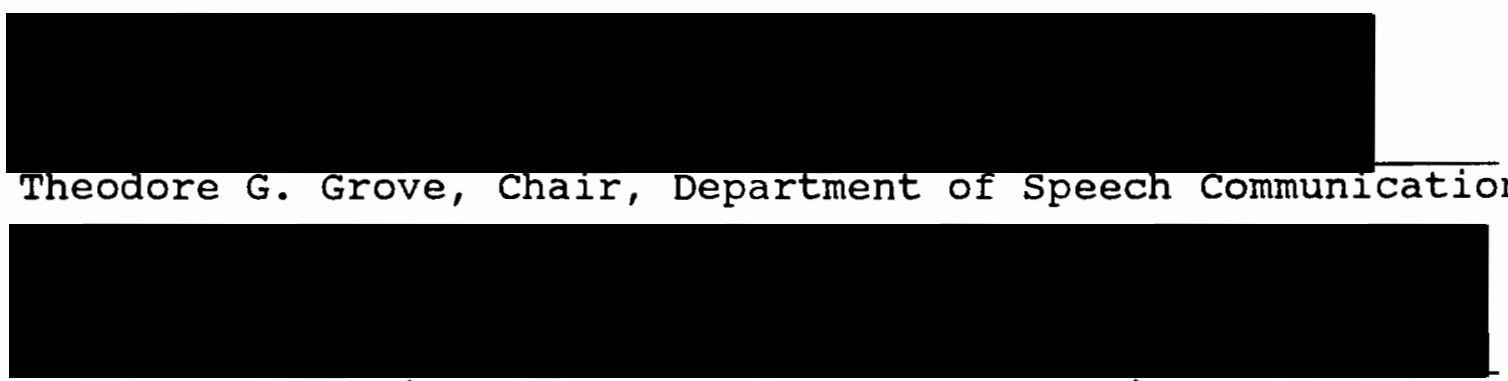

Bernard Ross, Vice Provost for Graduate Studies 
TO

TINA

JACQUELINE

MORRISON 


\section{ACKNOWLEDGEMENTS}

I would like to express my heartfelt thanks to my wife Tina, who helped me complete this project in more ways than I can count. I would also like to thank Donald Plapinger and Rodney Pelson for giving me the opportunity to share their research project. My most gracious thanks go to Thomas G. Dolan, who provided endless consultation on the subtle and complex methodological, theoretical, and statistical problems that I encountered. Last, but not least, a warm "thank you" to James F. Maurer, my program adviser and constant source of inspiration throughout my education at Portland State University. 
TABLE OF CONTENTS

PAGE

ACKNOWLEDGEMENTS . • . • . . . . . . . . . . . . iii

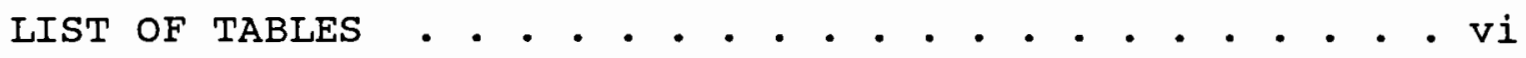
LIST OF FIGURES . . . . . . . . . . . . . . . . viii CHAPTER

I INTRODUCTION • • • • • . . . . . . . . . . 1

II REVIEW OF THE LITERATURE . . . . . . . . . 6 History of Auditory Training Prior to the Advent of Electronic Amplification . . . 7 Evolution of Auditory Training Devices after Electronic Amplification . . . . 8 Studies of the Electroacoustic Characteristics of FM Auditory Trainers and Hearing Aids . . . . . . . . . 17 Studies on Classroom Amplification Systems . . . . . . . . . . . . 24 Speech Perception in Noise, Reverberation, and with Auditory Training Devices . . 25 III METHODS . . . . . . . . . . . . . 30 Instrumentation . . . . . . . . 31 Hearing Aid-alone, Microphone Response . 35 Personal Mini-loop Response . . . . 35 Direct Audio Input Response . . . . . 36 
IV RESULTS . . . . . . . . . . . . . . . 38

Test Condition \#1 . . . . . . . . . 43

Test condition \#2 . . . . . . . . . 44

Test Condition \#3 ... . . . . . . . 45

Test Condition \#4 . . . . . . . . . 45

$\mathrm{V}$ DISCUSSION ............. . 55

REFERENCES CITED . . . . . . . . . . . . . . 67

APPENDICES

A FREQUENCY RESPONSE GRAPHS . . . . . . . . 70

B LETTER AND NUMBER CODES . . . . . . . . . . 80

C THE TOLERANCE METHOD FOR THE FREQUENCY

RESPONSE CURVE OF HEARING AIDS

(ANSI S3.22 1982, 6.10.1, 6.10.2) . 82 
LIST OF TABLES

TABLE

PAGE

I summary of Types of Amplification Systems

Currently in use in American Education . . . . . 16

II Test Conditions . . . . . . . . . . . . . . . 31

III Results of Frequency Response Tolerance Analysis

by Combination . . . . . . . . . . . . . . . 44

IV Results of Frequency Response Tolerance Analysis

by Test Condition . . . . . . . . . . . 46

V Means, standard Deviations, and Ranges of Data Points

Falling Outside the ANSI Frequency Response

Tolerance Limits using Personal Mini-loop Input . 48

VI Means, standard Deviations, and Ranges of Data Points

Falling Outside the ANSI Frequency Response

Tolerance Limits using Direct Audio Input . . . 49

VII Results of Three Factor ANOVA for Comparison of Mean

High Frequency Output Between Test Conditions,

FM Auditory Trainers, and Hearing Aids . . . . . 51

VIII Results of Three Factor ANOVA for Comparison of Mean

Low Frequency output Between Test Conditions,

FM Auditory Trainers, and Hearing Aids . . . . . 52 
IX Results of one Factor ANOVA and Multiple Comparison Tests on Mean Low Frequency Output Between Test Conditions . . . . . . . 53 $x$ Results of one Factor ANOVA and Multiple Comparison Tests on Mean Low Frequency output Between FM Auditory Trainers . . . . . . 54 


\section{LIST OF FIGURES}

FIGURE

PAGE

1 Schematic Diagram of Instrumentation for Measuring Frequency Response . . . . . . . . . . 34

2 Frequency Response Curves for the PE 600 PPCH-A coupled using Personal Mini-loop to the Phonic Ear System 4 Auditory Trainer . . . . . . . . . . . . 40

3 Frequency Response Curves for the UE 12 PPCL-A

coupled using Personal Mini-loop to the Telex TDR-4 Auditory Trainer loop . . . . . . . . . . . . 41

4 Frequency Response Curves for the UE 12 PPCL-A coupled using Direct Audio Input to the Comtek Companion Auditory Trainer. . . . . . . . . . . . . 42

5 Frequency Distribution for Data Points Falling Outside ANSI Frequency Response Tolerance Limits using Personal Mini-loop Input . . . . 48

6 Frequency Distribution for Data Points Falling Outside ANSI Frequency Response Tolerance Limits using Direct Audio Input . . . . . . . 49 


\section{CHAPTER I}

\section{INTRODUCTION}

The Personal Mini-loop and Direct Audio Input accessories are relatively recent innovations which allow frequency modulation (FM) auditory trainers to be interfaced with hearing aids. An FM auditory trainer system consists of two units: the transmitter and receiver. The transmitter includes a microphone, transmitter unit and antenna. This is worn by the teacher or parent with the microphone usually clipped onto the lapel. The system converts the teacher's voice into an electrical signal which then modulates a high frequency carrier, and broadcasts an FM radio signal. This radio signal is picked up by the receiver, which is usually worn by the hearing impaired student. The receiver demodulates the signal and directs it to the student's hearing aid. The receiver consists of a receiving antenna, an FM radio receiver circuit, an audio amplifier, a volume control and other output controls, and Personal Mini-loop or Direct Audio Input accessories for routing the audio signal to the hearing aid. Many auditory trainers are now capable of being interfaced with hearing aids of different manufacturers. 
The primary purpose of these systems is to provide the user with a high, signal-to-noise ratio. The signal-to-noise ratio is the ratio of the signal (in this case the speaker's voice) to the corresponding background noise. The auditory trainer overcomes the problem of conventional hearing aids where ambient noise is amplified equally along with the speech signal, causing a poor signal-to-noise ratio. Although ambient noise is also amplified in the FM system, the talker is effectively closer to the microphone, thus increasing the signal-to-noise ratio at the input to the system.

Auditory trainers are primarily used by schools and their mainstreamed hearing impaired students. In addition, these systems may be used in the home and other places such as auditoriums where the listener and speaker may be separated by sizable distances. For example, in a large auditorium the FM transmitter and microphone could be placed on the lectern to transmit the speaker's voice to the hearing impaired listener seated toward the rear.

There are two main configurations by which the signal from the FM receiver is directed to the hearing aid: Direct Audio Input and Personal Mini-loop. In the Direct Audio Input configuration, the signal from the receiver is routed directly into the hearing aid through a cord. At the hearing aid it is further amplified and converted into sound by the hearing aid receiver. The sound is directed to the ear in 
the usual manner for a hearing aid, through tubing and an earmold. In the Personal Mini-loop configuration, the electrical signal from the FM receiver is routed to a small wire loop worn around the neck. This neck loop emits an alternating magnetic field that is picked up by the telecoil of the hearing aid and transduced into electrical current. Again, the signal is amplified by the aid and transduced into sound by its receiver.

Unfortunately, the growing use of FM auditory training devices has not been accompanied by a like increase in knowledge about their electroacoustic interactions with various hearing aids. Since these systems are not classified as hearing aids and regulated as such, they are sometimes fitted and maintained by educational personnel who may not be qualified or equipped to fully assess their interaction. The result is that these systems may be used with little or no knowledge of where to set the volume control and other controls of the FM units and the hearing aid for optimum amplification. There is no current national standard specifying auditory trainer measurements, nor are there standards for combined auditory trainer and hearing aid measurements.

There is thus a need for studies to assess the compatibility of FM systems with various hearing aids. A number of researchers have attempted to address this issue. Van Tassel and Landin (1980) reported that the frequency 
responses of hearing aids changed unpredictably when the aids were coupled to an FM auditory trainer using a Personal Mini-loop. Freeman, Sinclair, and Riggs (1980) reported differences in the frequency response characteristics between the FM transmitter microphone and FM receiver environmental microphone modes. Hawkins and Van Tassel (1982) reported large variability in the frequency response of the Personal Mini-loop FM systems as compared to the microphone responses of the test hearing aids, but found minor differences when Direct Audio Input was used. Hawkins and schum (1985) observed large differences in frequency response comparisons using different coupling methods, but no single coupling method provided consistently better agreement with the hearing aid-alone response. They concluded that it cannot be assumed that the electroacoustic characteristics of a hearing aid are preserved when coupled to an FM auditory trainer using any means.

None of the prior studies have systematically inveștigated the effects of the interaction of the hearing aid, FM system, coupling method, and volume control setting on frequency response. Also, the number of combinations of hearing aids and FM auditory trainers has been relatively restricted in previous studies. Van Tassell and Landin (1980) investigated five FM auditory trainers in combination with one hearing aid using Personal Mini-loop input. Hawkins and Van Tassel (1982) used only one FM auditory trainer 
hearing aid combination for Direct Audio Input and two FM auditory trainers in combination with a different hearing aid for the Personal Mini-loop investigation. Hawkins and Schum (1985) used four hearing aids in combination with two FM auditory trainers, but only examined six of the eight possible combinations.

In this study we attempted to addressed these issues by analyzing the frequency response characteristics of three different hearing aids, alone and with interfaced with three different FM auditory trainers. The volume settings of the systems were parametrically varied. Analysis of the results should indicate whether it is better to set the hearing aid at a low gain setting and the FM receiver at a high setting, or vice versa. It may also reveal combinations of hearing aids and FM systems that are inappropriate due to undesirable changes in frequency response. This may have practical value to the classroom teacher managing students using these systems, and to the audiologist in fitting these systems. 


\section{CHAPTER II}

REVIEW OF THE LITERATURE

Saunders (1971) defines auditory training units as a subcategory of hearing aids, as:

"...any device capable of intensifying the sound reaching the person's ear. Out of this range of amplifiers, we have selected for discussion those which are applicable for use by hearing-impaired people. The nature of our definition emphasizes that there exists no essential difference between wearable hearing aids, auditory trainers, and group hearing aids. These units differ only in the degree of efficiency with which they are able to faithfully amplify sound, the degree to which we are able to modify and control that amplification, the mobility with which they provide the individual, and the specific nature of the task for which each unit is designed."

Saunders continues by defining auditory training as

"...a systematic procedure designed to increase the amount of information that a person's hearing contributes to his total perception."

This author will define auditory training units as electronic devices or hearing aids specifically designed for training the hearing impaired. These devices are characterized by a microphone which is held close to the talker's mouth, this signal is fed into an amplifier and delivered to the hearing impaired listener's hearing aid or receiver. These devices help the hearing impaired listener by improving the signal-to-noise ratio for the talker's voice. 
Most early classroom amplification systems were stationary desk units used principally for formal auditory training lessons. Hearing aids were wearable devices used to provide amplification at all other times. This distinction was broken down by the advent of classroom induction loop systems and wearable radio frequency devices, since these units can function both as auditory trainers and as conventional body aids (Byrne \& Christen, 1981).

HISTORY OF AUDITORY TRAINING PRIOR TO THE ADVENT OF ELECTRONIC AMPLIFICATION

The first reference in western literature of the importance of utilizing residual hearing was in the first century A.D. when Archigenes used a hearing trumpet to amplify sound. A similar ear trumpet was employed by Alexander the Great in the sixth century A.D. The first use of analytic exercises was in 1761 by Ernaud. In 1802 Itard claimed that the deaf could be trained to hear words. Toynbee in 1860 realized that the great advantage of auditory training is that "deaf mutes" can get auditory feedback from and learn to modulate their own voices (Pollack, 1970).

In the early 1900's, Dr. Max Goldstein was the first to use simple speaking tubes and megaphones to direct and amplify. the instructor's voice during "acoustic exercises". This was an integral part of his Acoustic Method approach 
(Pollack, 1970). This may have been the first "auditory training device" used in this country.

Two important landmarks in auditory training occurred in the first part of this century. The first was the development of the pure-tone audiometers in the 1920's (Newby, 1985). The second occurred two decades later in the middle forties when a relatively small body level hearing aid was developed which could be worn by very young children (Pollack, 1970). These two inventions paved the way for the identification and habilitation of hearing impaired children. As a result more auditory training was done in special schools leading to a more multi-sensory approach to language learning (Pollack, 1970).

EVOLUTION OF AUDITORY TRAINING DEVICES AFTER ELECTRONIC AMPLIFICATION

Auditory trainers can currently be divided into seven groups. These groups are listed roughly in order of development, Hardwired Desk-type, Wearable Loop Induction Systems, AM and FM Radio Frequency, and Infrared systems (Saunders, 1971), and possible future Digital Radio Frequency systems. The characteristics of these systems will be discussed in more detail in the following paragraphs.

The earliest auditory trainer systems were referred to as "hardwired" because all of the components were connected using wire. These devices represented a significant 
suffered from the limited knowledge of electronics. BY virtue of being "hardwired" these systems also offered limited mobility for the teacher, and zero mobility for the student. This restricted classroom activities as well as precluding use of the auditory training system outside the classroom. The earlier versions of these systems seldom provided for amplification of the student's voice, therefore limiting the feedback which is so necessary for speech production. This system also allowed the teacher to input signals from recorded material (Roeser and Downs, 1981; Saunders, 1971).

Desk-type auditory trainers offer a limited increase in mobility within the classroom, but because most of these systems relied on internal microphones for input, the same poor signal-to-noise ratio problems of personal hearing aids were encountered (Saunders, 1971). Because of the large size of these units, portability outside of the classroom was impractical.

Wearable auditory trainers are little more than large body hearing aids, although these devices often included the added advantage of true binaural amplification. The primary advantage of wearable auditory trainers is the increase in mobility for the users, since they could be used on field trips and at assemblies outside the classroom and building. The these systems suffer the same disadvantages of wearable 
hearing aids; poor signal-to-noise ratio, susceptibility to room reverberations, and low fidelity sound.

The loop induction system was developed in an attempt to increase mobility within the classroom, while providing a better signal-to-noise ratio, amplifying the teacher's voice and providing "consistent amplification" between the classroom the home (Roeser and Downs, 1981). These systems allowed the hearing impaired student to continue using his or her personal hearing aids in the classroom provided the hearing aids were equipped with telecoils. The basic system included a teacher microphone attached to a power amplifier which produced a magnetic field in a wire 10op placed in the classroom. This alternating magnetic field was picked up via magnetic induction by the telecoil in the hearing aid or wearable auditory trainer. The primary advantage of this system was increased mobility within the classroom. The disadvantages included poor acoustical performance, susceptibility to noise generated by other magnetic fields (especially fluorescent 1 ights), variation in the magnetic field strength and the acoustic output at the ear as the telecoil moved relative to the fixed classroom coil, and crosstalk between adjacent rooms equipped with induction loops (Roeser and Downs, 1981).

Radio frequency based auditory training systems are broken down into two types, amplitude modulation (AM) and frequency modulation (FM), because of problems and 
characteristics unique to each. AM auditory trainers may be used alone, similar to a body aid, or in conjunction with a personal hearing aid by means of a miniature magnetic induction loop worn around the neck. This is referred to as a Personal Mini-loop (PML), and is attached to the output of the auditory trainer. The Personal Mini-loop creates a small magnetic field around the neck of the wearer which is picked up through induction by a telecoil in the hearing aid. This signal is then amplified by the hearing aid, or in addition to the signal from the hearing aid microphone. The primary advantages of this system are increased mobility for the student and the teacher, provided the transmitter was not of the fixed variety. The signal-to-noise ratio is improved by use of radio transmission, but this is also a drawback since the receivers will pick up any stray signals from outside transmitters operating in a close frequency range. There is also a problem with crosstalk between classrooms, as well as variations in the signal strength due to interference from structural steel (Burgess, Christen, Donald, and Lowe; 1979).

Many AM systems used a fixed loop antenna, referred to as a "learning antenna", to help restrict the propagation of radio waves to the classroom. This helped to reduce crosstalk between classrooms, but greatly reduced mobility since the teacher was tied to the loop and could not venture outside the classroom. 
AM auditory training systems can provide a higher fidelity and more controlled sound pressure level for the teacher's voice, and as a result represented a significant improvement over induction loop amplification systems (Roeser and Downs, 1981).

Frequency modulation (FM) radio based auditory training systems are currently the most widely used in the education of the hearing impaired. FM auditory trainers were developed to overcome some of the shortcomings of AM based systems while retaining the advantages of mobility and a controlled sound pressure level for the teacher's voice. FM radio waves are not affected by structural steel (Burgess, Christen, Donald, and Lowe; 1979), they require no special installation since the majority of the teacher transmitters and all student receivers are battery operated and worn on the person. This feature allows great mobility for both teacher and student inside and outside the classroom.

These systems are less susceptible to outside interference since 1976 when the Federal Communications Commission allocated the frequency range between 72 and 76 MHz for use in education of hearing impaired students. This provides 32 different frequency bands, allowing use of many different frequencies within the same school to reduce crosstalk between classrooms (Roeser and Downs, 1981).

FM auditory trainer systems may be interfaced with the student's hearing aid using the Personal Mini-loop and 
telecoil mentioned above, or a Direct Audio Input (DAI) connection. The Direct Audio Input method allows FM auditory trainers to be used with hearing aids which are not equipped with telecoils, as well as eliminating most of the disadvantages of the Personal Mini-loop which will be discussed later. Most are equipped with internal microphones which allow the student to receive environmental sound as well as monitor his or her own voice. True binaural amplification is available through the environmental microphones on some of these systems. Some FM auditory training systems allow full duplex communication between student units (Roeser and Downs, 1981).

Infrared based auditory training systems represent a new approach to the problem of how to provide an optimal auditory signal to the hearing impaired student. This system uses infrared light emitting diodes to transmit the teacher's voice to the student receiver. These systems are primarily used as assistive listening devices in auditoriums and concert halls because of their excellent sound quality and ability to provide a true binaural signal. These systems are being used in some schools for the same reasons; however, there are some drawbacks. The majority of these systems must be permanently installed, thus eliminating mobility outside the classroom. Although there is no interference from radio frequency energy, infrared light from the sun and incandescent lamps can interfere with the 
signal. Also, since light waves are used, the transmitter and receiver must be in line of sight for signal reception. Until the problems of mobility and interference from other light sources are solved, infrared systems will find little use in school settings (Roeser and Downs, 1981).

The newest technology in the field of audio is the digital recording and transmission of sound. The great success of the compact disk is a testament to the superb quality this medium offers. Digital technology may soon be applied to auditory trainers. The basic system would consist of a teacher transmitter and control unit. This could be a small wireless microphone worn around the neck with a remote control unit, or a hardwired microphone with a desk top transmitter and control unit. The teacher's voice would be converted from an analog to a digital signal by an analog to digital converter chip, then it would be transmitted as a series of digital pulses of radio frequency energy. The pulses would be received by the student unit and the series of digital pulses would be converted by a digital to analog converter chip into a signal which would be amplified and sent to the student's hearing aid or earphones.

Digital radio frequency auditory trainers would solve most of the problems inherent in the other systems and confer versatility beyond anything currently available. True binaural signals could be transmitted using only one carrier frequency. The teacher could control which student units 
received the signal. This would allow more individual attention to a particular student's needs without broadcasting to all of the other students in the classroom. It would allow the impromptu formation of small groups within the classroom. The circuitry of the student unit could be built to send a digital message to the teacher control unit to warn of low battery voltage or other malfunctions, thus reducing the need to constantly monitor the operating status of each unit. Each student unit could be designed to operate as a full duplex, binaural system. This would allow each student to communicate freely with other students in the same classroom with the same benefits of superior sound quality. The environmental microphones on each unit could be programmed to turn on only when the sound level reached a predetermined level. This would allow the student to monitor his or her own voice or the voices of others nearby, then turn off when not in use to reduce the environmental noise coming into the system. Each unit could be programmed to equalize its frequency response to provide truly consistent amplification. The list of possibilities are only limited by the imagination of the engineers who create such a system. The author knows of no digital auditory training system currently in use or under development.

The prevalence of different forms of classroom amplification systems was investigated by sinclair and 
Freeman in 1981 (see Table I). These results indicate that excluding personal hearing aids, FM auditory trainers combined with personal hearing aids are the most prevalent system.

TABLE I

SUMMARY OF TYPES OF AMPLIFICATION SYSTEMS CURRENTLY IN USE IN AMERICAN EDUCATION

$$
N=1,871
$$

Type of system

Percentage

of

Classrooms

Personal hearing aid

$84 \%$

FM wireless

$26 \%$

FM wireless combined

with personal hearing aid

$31 \%$

personal-loop aid

6\%

desk-mounted

$2 \%$

room-loop

18

(induction loop

amplification systems)

From J.S. Sinclair and B.A. Freeman (1981). The status of classroom amplification in American Education.

FM auditory trainers used alone were the next most prevalent. In the eight years since this survey, the use of FM auditory trainers probably has increased, and Direct Audio Input was introduced. 
STUDIES OF THE ELECTROACOUSTIC CHARACTERISTICS OF FM AUDITORY TRAINERS AND HEARING AIDS

Van Tassel and Landin (1980) describe a series of investigations where the performance of several hearing aids in combination with an FM auditory trainer were compared in a classroom setting and in an audiologic clinic. Electroacoustic analysis was carried out using a Fonix Type 5000 Hearing Aid Test Set and a 2 Cc hard walled coupler $(\mathrm{HA}-2)$.

Performance was evaluated using three operating modes. These are best described by sequentially listing the input, coupling, and output modes: 1) FM microphone, transmitter, student receiver, insert earphone, 2) FM microphone, transmitter, student receiver, mini-loop, hearing aid, and 3) environmental microphone, student receiver, insert earphone. They reported that the frequency responses of five personal hearing aids as measured with the hearing aids on microphone input differed unpredictably from the frequency responses measured when the aids were coupled to an FM auditory trainer using a Personal Mini-loop. They also reported that the output using the environmental microphone input (mode 3) was as much as $18 \mathrm{~dB}$ higher as compared to the F.M. microphone input (mode 2 ) when measured at the same volume control settings.

Although a statistical analysis was not performed, useful conclusions were reached by comparing the classroom 
with the clinic measurements. The primary conclusion reached was that classroom performance could not be predicted from clinic performance. Van Tassel and Landin's results showed that the output of the environmental microphone, FM receiver, and insert earphone was uniformly higher than that of the teacher microphone, transmitter, FM receiver, and insert earphone. This difference was as great as $18 \mathrm{~dB}$, and challenges the notion that this type of system is providing an improved signal-to-noise ratio for the teacher's voice. They concluded that the higher gain from the environmental microphone may eliminate any improvement in signal-to-noise ratio for the teacher's voice, making the situation worse than if the student was using only his or her personal hearing aid.

A potential problem with this study was the use of nonstandard measurement procedures to evaluate the hearing aid FM auditory trainer response. This response was then compared to the hearing aid microphone response which was measured according to ANSI S3.22 1976 standards. This may have introduced some measurement error.

Freeman, Sinclair, and Riggs (1980) investigated the electroacoustic performance of FM auditory trainers. Two primary objectives were addressed: first, what are the electroacoustic differences between the frequency modulation (FM) and environmental microphone (EM) input modes? and second, can the methods used for evaluating the performance 
of hearing aids be successfully used with FM auditory trainers?

The initial plan was to compare the electroacoustic measurements with the manufacturers' specifications. It was soon realized this would be pointless since there was little or no consistency in the manufacturers' methods of measurement or reporting procedures. The input mode and input SPL were often unspecified.

Freeman, Sinclair, and Riggs (1980) compared output between the FM microphone and environmental microphone input modes. They reported differences in the frequency response characteristics between the FM microphone and environmental microphone modes, and suggested that both modes be evaluated separately to assess performance fully. They concluded that with certain cautions the ANSI S3.22-1976 procedures could be applied to the electroacoustic measurement of FM auditory trainers. Internal noise levels in the FM microphone mode increased as the FM volume control setting was increased. These levels ranged from 50 to $124 \mathrm{~dB}$ SPL. This study showed significant differences in the frequency response curves of the environmental compared to the FM microphones. However, since the FM auditory trainers were evaluated alone while driving a button receiver, these results only apply indirectly to FM auditory trainers coupled with hearing aids. 
Sinclair, Bess \& Riggs (1981) investigated the saturation output, gain, total harmonic distortion, and internal noise output of hearing impaired childrens' FM auditory trainers in the as-worn and full-on gain settings. The median high-frequency average saturation output was 134 dB SPL, gain measurements ranged from 30 to $70 \mathrm{~dB}$, and total harmonic distortion was found to be very low. The amount of gain was analyzed as a function of each child's hearing loss. Interestingly, there appeared to be no relationship between the amount of full-on or as-worn gain and the degree of hearing loss. These results support the idea that most of these auditory trainers are not fitted properly.

Hawkins and Van Tassel (1982) investigated the electroacoustic characteristics of four hearing aids interfaced using Personal Mini-loop and Direct Audio Input with one FM auditory trainer. SSPL9O and frequency response, equivalent input noise levels, and FM volume control taper curves were obtained from four hearing aids in the microphone mode and compared to the responses obtained when the same hearing aids were coupled to the test FM auditory trainer. The study reported large variability in the frequency response of the Personal Mini-loop FM systems as compared to the microphone response of the test hearing aids. However, only minor differences were observed when Direct Audio Input response was compared to the microphone response. 
One problem with this study was that only one hearing aid was investigated using Direct Audio Input, and it was combined with a single FM auditory trainer. Another problem may be the way in which the FM volume control was set and the choice of input levels. While coupled to the test hearing aid set at reference test gain position, the volume control of the FM auditory trainer was set so that the gain at $1000 \mathrm{~Hz}$ with a $60 \mathrm{~dB}$ SPL input equaled that of the hearing aid-alone at reference test gain position with the same input. This was referred to as 'Equivalent $1 \mathrm{kHz}$ Gain Position' (EIKGP). This was done to ensure that the overall gain of a given hearing aid FM auditory trainer combination was roughly the same as for the hearing aid-alone. The input to the FM microphone was a constant $60 \mathrm{~dB}$ SPL, which does not reflect the typical use conditions for such a system where the input originates approximately 6 inches from the microphone and has an average overall level of 84 dB SPI (Byrne and Christen, 1981).

Hawkins (1984) compared the speech recognition in noise of hearing impaired children using hearing aids and FM systems. He found the FM system gave the equivalent of $15 \mathrm{~dB}$ in improvement in signal-to-noise ratio as compared to personal hearing aids. This advantage disappeared when the hearing aid microphone was on while used with the FM auditory trainer. 
Hawkins and Schum (1985) investigated a variety of electroacoustic characteristics of four different hearing aids coupled with two different FM auditory trainers using Direct Audio Input, Personal Mini-loop, and silhouette inductor. Large differences were observed between some frequency response comparisons, but no single coupling method provided consistently better agreement with the hearing aid-alone response. Similar harmonic distortion and equivalent input noise levels were observed between the hearing aids and hearing aid FM auditory trainer combinations, except with the silhouette inductor which gave consistently higher levels for both. They concluded that it cannot be assumed that the electroacoustic characteristics of a hearing aid are preserved when coupled using any of the methods studied.

One limitation of this study is that although a higher input level ( $84 \mathrm{~dB}$ SPL) was used at the FM microphone during Direct Audio Input and Personal Mini-loop evaluations, this was compared to the hearing aid microphone responses obtained using an input of $60 \mathrm{~dB}$ SPL. Again, the FM receiver volume control was adjusted so that the output at $1000 \mathrm{~Hz}$ matched that of the hearing aid-alone. Their observation that similar equivalent input noise levels were observed between hearing aids and hearing aid FM auditory trainer combinations may refute the findings of Freeman, Sinclair and Riggs (1980). This study may be flawed since 
frequency responses of hearing aids measured using a $60 \mathrm{~dB}$ SPL input are compared with frequency responses of hearing aids combined with FM auditory trainers measured using an 84 aB SPL input.

Hawkins and Van Tassel (1982) and Hawkins and Schum (1985) both used 'Equivalent $1 \mathrm{kHz}$ Gain Position' (E1KGP) to set the volume control of the FM auditory trainer while coupled with the hearing aid. This is defined as the FM receiver volume control setting which yields the same sound pressure level at $1 \mathrm{kHz}$ when interfaced with a hearing aid set at reference test gain position as the hearing aid-alone set at reference test gain position yields (note that in Hawkins' 1985 study two different input levels were used together with ElKGP settings). This results in two frequency response curves which intersect at $1 \mathrm{kHz}$, which means that there may be variations in frequency response above or below $1 \mathrm{kHz}$. Since the ANSI S3.22 (1982) frequency response variation template is divided into low and high frequency regions at $2 \mathrm{kHz}$, it seems more appropriate to attempt to match the two outputs as close to $2 \mathrm{kHz}$ as possible. This will be addressed in the proposed study by matching the frequency response curves at the high frequency average of $1,1.6$, and $2.5 \mathrm{kHz}$.

No study has applied the ANSI S3.22 (1982) standards to the measurement of hearing aids in combination with FM auditory trainers. While IEC 118-3 (1979) does address the 
measurement of "hearing aid equipment not entirely worn on the listener," it has been criticized by Freeman, Sinclair, and Riggs (1980). They stated that the IEC 118-3 guidelines were "insufficient for laboratory use at present." This is because it does not control for variables (volume control settings, input method, and appropriate signal input levels) which their 1980 study showed can significantly alter the frequency response of FM auditory trainer systems. The proposed study will attempt to address this issue by applying the ANSI S3.22 (1982) standards while controlling for the variables omitted by the IEC 118-3 (1976) standard.

\section{STUDIES ON CLASSROOM AMPLIFICATION SYSTEMS}

Matkin and olsen (1970) found that classroom induction loop amplification (ILA) systems were often defective or not operating at optimum efficiency. Problems included improper control settings, defective amplifiers, and impedance mismatches. These conditions would result in poor speech intelligibility at best, or no intelligible signal at worst, regardless of the condition of the student's personal hearing aid.

Sung, Sung, Hodgson and Angelelli (1976) found a slightly poorer low-frequency response and a deep notch at about $2,500 \mathrm{~Hz}$ in the acoustic response of ten body-type aids when evaluated through a classroom induction loop amplification system as compared to laboratory measurements. 
SPEECH PERCEPTION IN NOISE, REVERBERATION, AND WITH AUDITORY TRAINING DEVICES

Vargo, Taylor, Tannahill and Plummer (1970) evaluated the speech intelligibility of a dedicated "loop aid" and a conventional body hearing aid using microphone input and telecoil input through a classroom induction loop amplification system. They found significantly higher speech discrimination for monosyllables (CID W 22) on both microphone and telecoil input modes for the conventional body aid. Discrimination for the loop aid was significantly lower for both input modes, with the lowest intelligibility while on inductance coil input mode. Nabelek, Donahue, and Letowski (1986) Compared the performance of three classroom amplification systems based on audio induction loop, F.M. radio frequencies, infrared light and an acoustic based public address (PA) system. Performance was evaluated using 4 groups of listeners: normal, hearing impaired, hearing aid users and the elderly. These groups were administered the Modified Rhyme Test under two conditions, with multitalker babble at a signal-to-noise ratio of $+8 \mathrm{~dB}$ and without the multitalker noise at $+20 \mathrm{~dB}$. Analysis of variance revealed that the main effects of room signal-to-noise ratio, groups, and systems were significant. All of the listening systems provided significantly better scores with all the groups than the PA system. 
Picard and Lefrancois (1986) measured speech perception through FM auditory trainers in noise and reverberation. The results indicated an overwhelming advantage of FM transmission for maintaining speech intelligibility in noise and reverberation.

Hodgson and sung (1972) investigated the intelligibility of speech through two hearing aids operating on either microphone or telecoil inputs. Their results indicated that frequency response appeared to determine the performance difference regardless of input mode. The better frequency response in the region below $1 \mathrm{kHz}$ in telecoil input mode appeared to increase sentence intelligibility as compared to microphone mode.

Sung, Sung, and Angelelli (1971) studied the effects of frequency response characteristics of hearing aids on speech intelligibility in noise. They found that in normals and subjects with a mild-to-moderate sensorineural hearing loss, extended low frequency response below $500 \mathrm{~Hz}$ caused slightly poorer scores for monosyllabic words (NU-6 words in speech noise at $a+6 \mathrm{~dB}$ signal-to-noise ratio). The authors speculated that this was probably due to greater amplification of speech noise and a resultant upward spread of masking.

Sung \& Hodgson (1971) compared speech intelligibility in hearing aids using microphone and telecoil input. They found that hearing aids with better high frequency response 
produced higher discrimination scores with monosyllabic words with both input modes. The frequency response characteristics of the hearing aid circuitry was the most important factor in high speech discrimination. Increased gain below $1 \mathrm{kHz}$ on telecoil input resulted in increased speech intelligibility for connected discourse, but poor high frequency response resulted in decreased intelligibility for monosyllabic words. This is consistent with the findings of Giolas and Epstein (1983) which indicate that connected discourse is less affected by poor frequency response as compared to discrete words.

Van Tassel, Mallinger, and Crump (1986) investigated functional gain and speech recognition using an FM auditory trainer and insert earphone as compared to the same FM auditory trainer interfaced using a Personal Mini-loop to a hearing aid. The insert earphone and FM auditory trainer provided more functional gain, especially below $1000 \mathrm{~Hz}$. Word discrimination scores did not vary significantly between the two conditions.

Nabelek and Pickett (1974) studies the effects of noise and reverberation on monaural and binaural speech perception through hearing aids. Reverberation times of 0.3 and 0.6 seconds were incorporated with signal-to-noise ratios varying from $+35 \mathrm{~dB}$ to $-15 \mathrm{~dB}$. The longer reverberation time caused a significant decrease in performance of both groups. The hearing impaired subjects 
performed 78 poorer under the longer reverberation time in quiet and in noise. The hearing impaired subjects also showed a binaural advantage of $1.5 \mathrm{~dB}$ under all listening conditions.

Crum and Matkin (1976) performed acoustic evaluations on 11 classrooms assigned to teachers of the hearing impaired. Each room was evaluated for ambient noised levels and acoustic treatment to reduce reverberation. This information was analyzed by an acoustical engineer. The findings suggest that only one of the 11 classrooms provided an acceptable acoustic environment for teaching hearing impaired children. Of the remaining 10 rooms, only six were judged as being acceptable if modifications were made to abate noise and reverberation. The remaining four were judged as totally unacceptable. Modification was not considered a cost effective solution.

Finitzo-Hieber and Tillman (1978) studied the effects of reverberation and noise on monosyllabic word discrimination in normal and hearing impaired children. The normal group scored significantly higher than the hearing impaired group under all conditions. It was concluded that classroom acoustics should be considered a critical variable in the educational environment of hearing impaired children. From the above review of the literature, it should be evident that although a large amount of time and energy has been expended on the study of variables which affect hearing 
impaired children in the classroom, much more work remains to be done. To this end, researchers have devoted themselves to the study of these problems. Until recently, the best solution was the use of classroom amplification systems with classes of hearing impaired children. Since PL 94-142, we have seen many of these children integrated into the regular classroom. This has necessitated the use of new approaches, such as the FM auditory trainer. However, with this new approach, new problems have been encountered, which cumulatively reflect the need for additional research with respect to the effects of these systems on the performance of personal hearing aids.

only a few studies have been reported on the effects of coupling methods on the frequency response of personal hearing aids (Van Tassel and Landin, 1980; Hawkins and Van Tassel, 1982; and Hawkins and Schum, 1985). To further investigate this area, this study examines the frequency response of FM auditory trainers and hearing aids coupled using Personal Mini-loop and Direct Audio Input methods. 
CHAPTER III

METHODS

Frequency response curves were obtained on three different hearing aids. Frequency response curves were then obtained on these same hearing aids in combination with three different FM auditory trainers under four different conditions. For the first two conditions, the hearing aids were coupled to the FM auditory trainers using the appropriate Personal Mini-loop. For the last two conditions, the appropriate Direct Audio Input cord was used to couple the devices. For input mode, frequency response curves were obtained using two volume control settings, first by setting the FM auditory trainer to full-on gain and adjusting the hearing aid to reference test gain position, and then by setting the hearing aid to full-on gain and adjusting the FM auditory trainer to reference test gain position. These test conditions are summarized below (see Table II).

These four test conditions were applied to each of the nine hearing aid and FM system combinations for a total of thirty-six combinations. The three factors are the test condition, the hearing aid model, and the FM system model 
TABLE II

TEST CONDITIONS

\begin{tabular}{|c|c|c|c|c|}
\hline Control & Cond. \#1 & Cond. \#2 & Cond. \#3 & Cond. \#4 \\
\hline \multirow{2}{*}{$\begin{array}{l}\text { Hearing } \\
\text { aid alone } \\
\text { reference } \\
\text { test gain } \\
\text { position }\end{array}$} & \multicolumn{2}{|c|}{ Personal Mini-loop } & \multicolumn{2}{|c|}{ Direct Audio Input } \\
\hline & $\begin{array}{l}\text { HA at ref } \\
\text { test gain } \\
\text { position, } \\
\text { FM full- } \\
\text { on gain }\end{array}$ & $\begin{array}{l}\text { FM at ref } \\
\text { test gain } \\
\text { position, } \\
\text { HA full- } \\
\text { on gain }\end{array}$ & $\begin{array}{l}\text { HA at ref. } \\
\text { test gain } \\
\text { position, } \\
\text { FM full-on } \\
\text { gain }\end{array}$ & $\begin{array}{l}\text { FM at ref. } \\
\text { test gain } \\
\text { position, } \\
\text { HA full-on } \\
\text { gain }\end{array}$ \\
\hline
\end{tabular}

\section{INSTRUMENTATION}

Pure tone signals at quarter octave intervals from 100 to $10,000 \mathrm{~Hz}$ were generated by the audio oscillator circuit of the Fonix z-5500. The signal was delivered to a single element loudspeaker located in the Fonix 5010 hearing aid test box. This instrument was calibrated using the Fonix calibration phone to bring the output at the speaker in the Fonix 5010 hearing aid test box to within manufacturer's specifications. In addition, the Fonix z-5500 was automatically calibrated prior to the measurement of each hearing aid and hearing aid FM auditory trainer combination. For all hearing aid-alone conditions SSPL9O and frequency response measurements were made according to the Fonix z-5500 instruction manual. The hearing aid was placed in the hearing aid test box (Fonix 5010) with its microphone at the calibration point. The hearing aid was coupled to an HA-2 coupler using $25 \mathrm{~mm}$ of No. 13 thick tubing. This set up 
produced a coupling system with dimensions identical to those described in ANSI S3.22 (1982) standards for the electroacoustic measurement of hearing aids. The HA-2 coupler was terminated by an electret microphone. Sound pressure levels were read and printed automatically by the Fonix z-5500 thermal strip printer.

For all combined hearing aid and FM auditory trainer measurements, each hearing aid was mounted on the left ear of a Knowles Electronics Manikin for Acoustic Research (KEMAR), which was placed on the floor of the test room. The hearing aids were coupled to an $\mathrm{HA}-2$ coupler and pressure microphone as described above. The coupler was placed inside the manikin head with a $25 \mathrm{~mm}$ piece of No. 13 thick tubing exiting the canal of the left rubber ear. The tube was connected to the earhook of the hearing aid. All testing was done with both of KEMAR's neck extension rings absent to more closely approximate a child's body size (Figure 1). The three FM systems used in this study were the Comtek Companion, the Phonic Ear System 4, and Telex TDR-4. These units where chosen because they had Direct Audio Input and Personal Mini-loop accessories which allowed them to be interfaced with any of the three hearing aids used in this study. They are also representative of the FM auditory trainers currently in use.

The three hearing aids used were the Unitron UE 12 PPCL-A, Telex 372 L-A, and Phonic Ear PE 600 PPCH. All these 
units met ANSI 1982 S3.22 specifications. These hearing aids were selected for their high gain, similar frequency responses and linear amplifier characteristics. They are all equipped with telecoils and Direct Audio Input jacks and are representative of hearing aids commonly used with FM auditory trainers. The external controls on all four instruments were set to provide the widest possible frequency response and highest possible output.

For the measurement of SSPL9O and frequency response curves for the Direct Audio Input condition, the appropriate adapter boot and cord were placed on the hearing aid and connected to the FM receiver. The receiver was taped to the upper right hip area of KEMAR, as if it were clipped to the belt of a user (see Figure 1).

For the measurement of SSPL90 and frequency response curves in the Personal Mini-loop condition, the same arrangement described above was used for the Direct Audio Input condition. The Direct Audio Input adapter boot and cord were removed and the hearing aid input set to telecoil. The appropriate Personal Mini-loop was placed around KEMAR's neck as it would have been placed on a user. This was taped in placed to eliminate any shift in position during and between measurements. The Personal Mini-loop was connected to the FM receiver, and the receiver was again taped to KEMAR's side. 


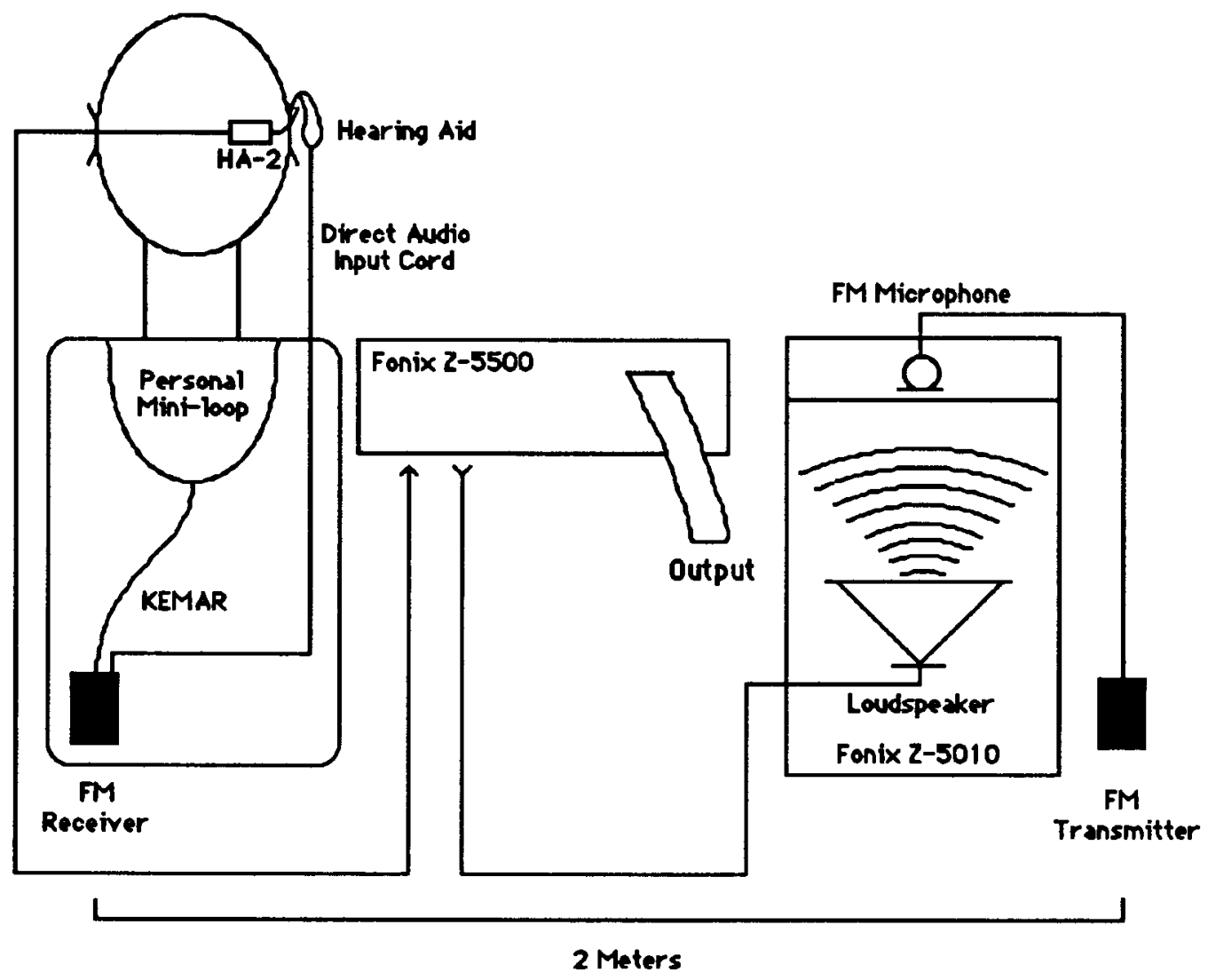

Figure 1. Schemotic diogram of instrumentation setup for measuring frequency responses of hearing aids combined with FM auditory trainers. 
The FM transmitter unit was placed 2 meters from the FM receiver, with their front panels facing each other. The FM transmitter microphone was placed in the calibrated location of the Fonix 5010 hearing aid test box.

HEARING AID-ALONE, MICROPHONE RESPONSE

Saturation Sound Pressure Level $90 \mathrm{~dB}$ (SSPL90) and frequency response curves were obtained on the three hearing aids using microphone input. Pure tones at 90 and 60 dB SPL were used as input to measure SSPL90 and frequency response curves, respectively. The internal adjustments for the hearing aids were set in accordance with ANSI S3.22 (1982) standards to produce the widest frequency response and maximum output. The hearing aid volume control settings were set to full-on gain for SSPL90, and set to reference test gain position for frequency response measurements. This is referred to as the RTGP \#1, or control condition.

\section{PERSONAL MINI-LOOP RESPONSE}

The FM transmitter microphone was placed in the calibrated location of the Fonix 5010 hearing aid test box. The corresponding FM receiver was located 2 meters from the transmitter. The Personal Mini-loop was taped around KEMAR's neck as described above and the hearing aid was set to the telecoil position. The volume control positions of both the hearing aid and FM auditory trainer were set to full-on gain 
for measurement of the SSPL90 curve. The frequency response curve of each combined system were found under four conditions.

In Test condition \#1, the volume control of the FM receiver was set to full-on gain and the volume control of the hearing aid adjusted to reference test gain position (defined by ANSI S3.22 (1982) as the gain setting where the average SPL of 1000,1600 , and $2500 \mathrm{~Hz}$ with a $60 \mathrm{~dB}$ SPL input is equal to the average SPL of the same three frequencies minus $17 \pm 1 \mathrm{~dB}$ with a $90 \mathrm{~dB}$ SPL input). This combination of volume control settings is referred to as Reference Test Gain Position \#2 (RTPG \#2). Under Test Condition \#2, the volume control of the hearing aids were set to full-on gain and the volume control of the FM receiver adjusted to achieve reference test gain position according to ANSI 53.22 (1982). This combination of volume control settings is referred to as Reference Test Gain Position \#3 (RTGP \#3). All other control settings were the same as in test condition \#1.

\section{DIRECT AUDIO INPUT RESPONSE}

This procedure followed that used for the Personal Mini-loop response with the following differences. The Personal Mini-loop was removed and the Direct Audio Input boot and cord were used to connect the hearing aid to the FM receiver. The hearing aid microphone was turned off to 
Direct Audio Input testing. This was not necessary for Personal Mini-loop input since all the hearing aids were in the telecoil mode which by-passes the hearing aid microphone. SSPL90 and frequency response curves under Reference Test Gain Position \#2 and \#3 conditions were obtained as described above. Under Test condition \#3 the hearing aid volume control was set to reference test gain position and the FM auditory trainer set to full-on gain, and under Test condition \#4 the hearing aid volume control was set at full-on gain and the FM volume control was adjusted to Reference Test Gain Position \#3. 


\section{CHAPTER IV}

\section{RESULTS}

Frequency responses were obtained for all combinations of the three hearing aids, three FM auditory trainer systems, and four Test conditions (coupling and volume control settings). The Tolerance Method for the Frequency Response Curve of hearing aids (ANSI S3.22 1982 6.10.1, 6.10.2) was used in this study for the qualitative analysis of the data on a discrete frequency by frequency basis, although this standard does not address the measurement of FM auditory trainers. It describes a tolerance template, composed of the upper and lower limits of variation in frequency response curve values superimposed on the hearing aid microphone frequency response curve. This procedure is described in detail in Appendix C. Briefly, the tolerance range is separated into high and low frequency bands. The low band extends from the lower limit to $2000 \mathrm{~Hz}$ with a range of variation of $\pm 4 \mathrm{~dB}$, the high band extends above $2000 \mathrm{~Hz}$ to the upper limit with a range of variation of \pm 6 $\mathrm{dB}$ from the hearing aid frequency response curve.

This tolerance template must remain square with the axes of the frequency response curve being measured, with any amount of vertical shift as well as horizontal shifts of 
\pm 108 in frequency allowed (ANSI 53.22 1982). These adjustments are referred to as template shifts in this study. The only two combined frequency response curves which fell entirely within the ANSI frequency response tolerance range with no template shift are shown in Figure 2. The testing of all hearing aids was completed successfully while coupled by means of Direct Audio Input and Personal Mini-loop to the Phonic Ear System 4 FM auditory trainer. In the case of the Telex TDR-4 FM auditory trainer and the UE 12 PPCL-A hearing aid, difficulties were encountered using the Personal Mini-loop. Specifically, insufficient gain was observed under Test Condition \#1 (Personal Mini-loop and Reference Test Gain Position \#2). As a result, it was not possible to obtain enough output to match the SSPL90 High Frequency Average minus $17 \mathrm{~dB} \pm 1 \mathrm{~dB}$, even with the hearing aid volume control set to full-on gain (Figure 3).

Problems were also encountered during testing of the Unitron UE 12 PPCL-A hearing aid and Comtek companion FM auditory trainer under Test condition \#4. The units were coupled using Direct Audio Input with the volume control of the hearing aid set to full-on gain and the FM auditory trainer volume control set to Reference Test Gain Position \#3. Under these conditions, it was not possible to reduce the output of the combined system enough to reach Reference Test Gain Position \#3, even with the FM receiver volume 


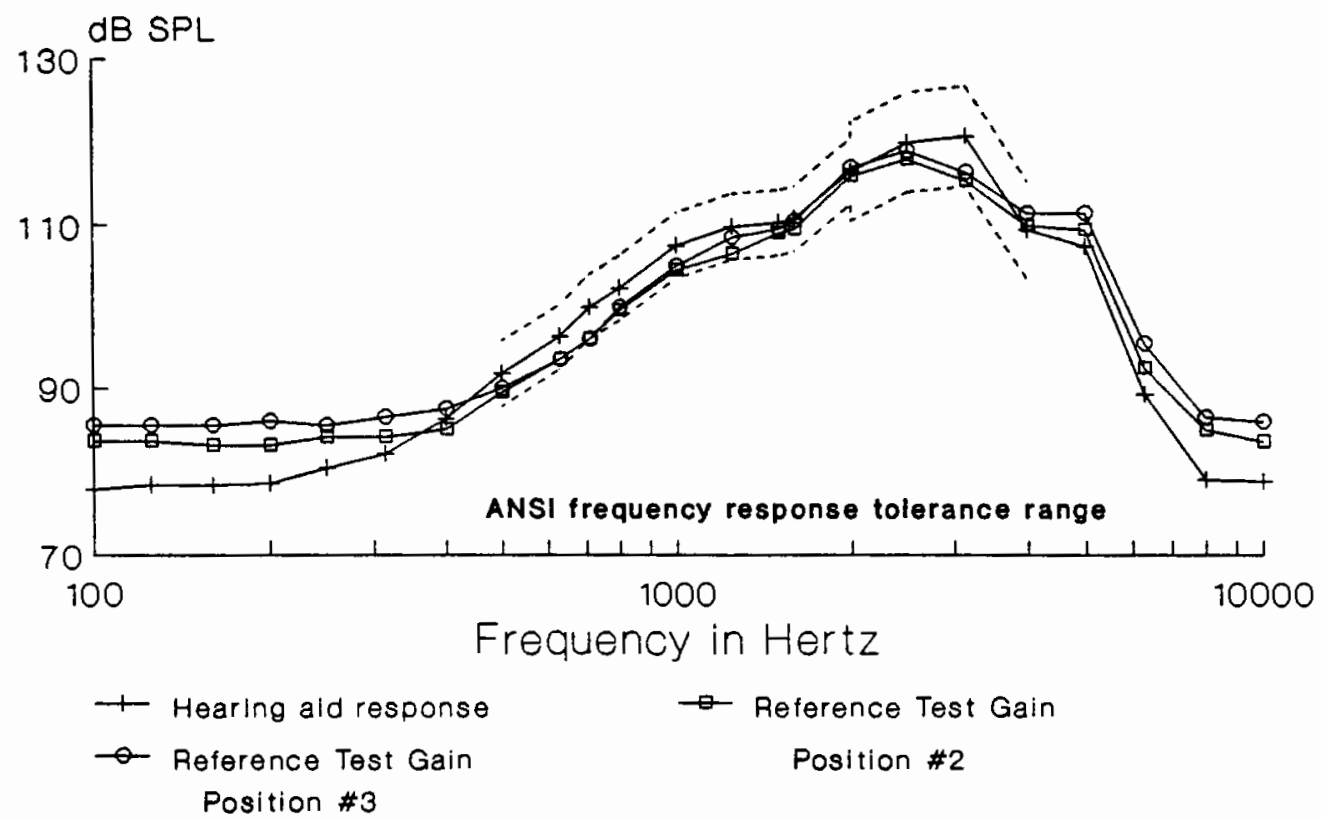

Figure 2. Frequency response curves for the PE 600 PPCH $-A$ coupled using Personal Miniloop to the Phonic Ear System 4 auditory trainer. Input level was set at $60 \mathrm{~dB}$ SPL. 


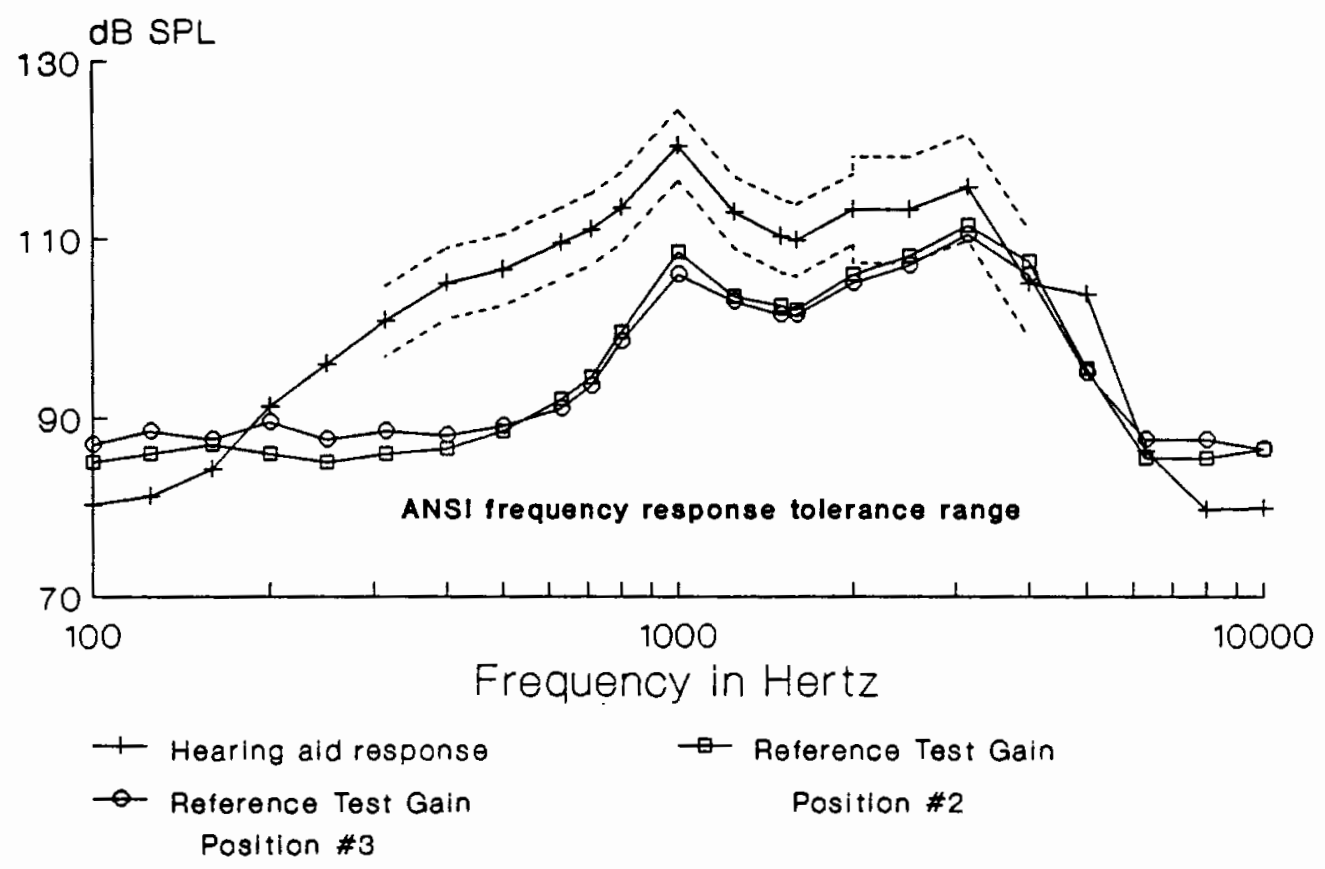

Figure 3. Frequency response curves for the UE 12 PPCL-A coupled using Personal Mini-loop to the Telex TDR-4 auditory trainer. Input level was set at $60 \mathrm{~dB}$ SPL. 


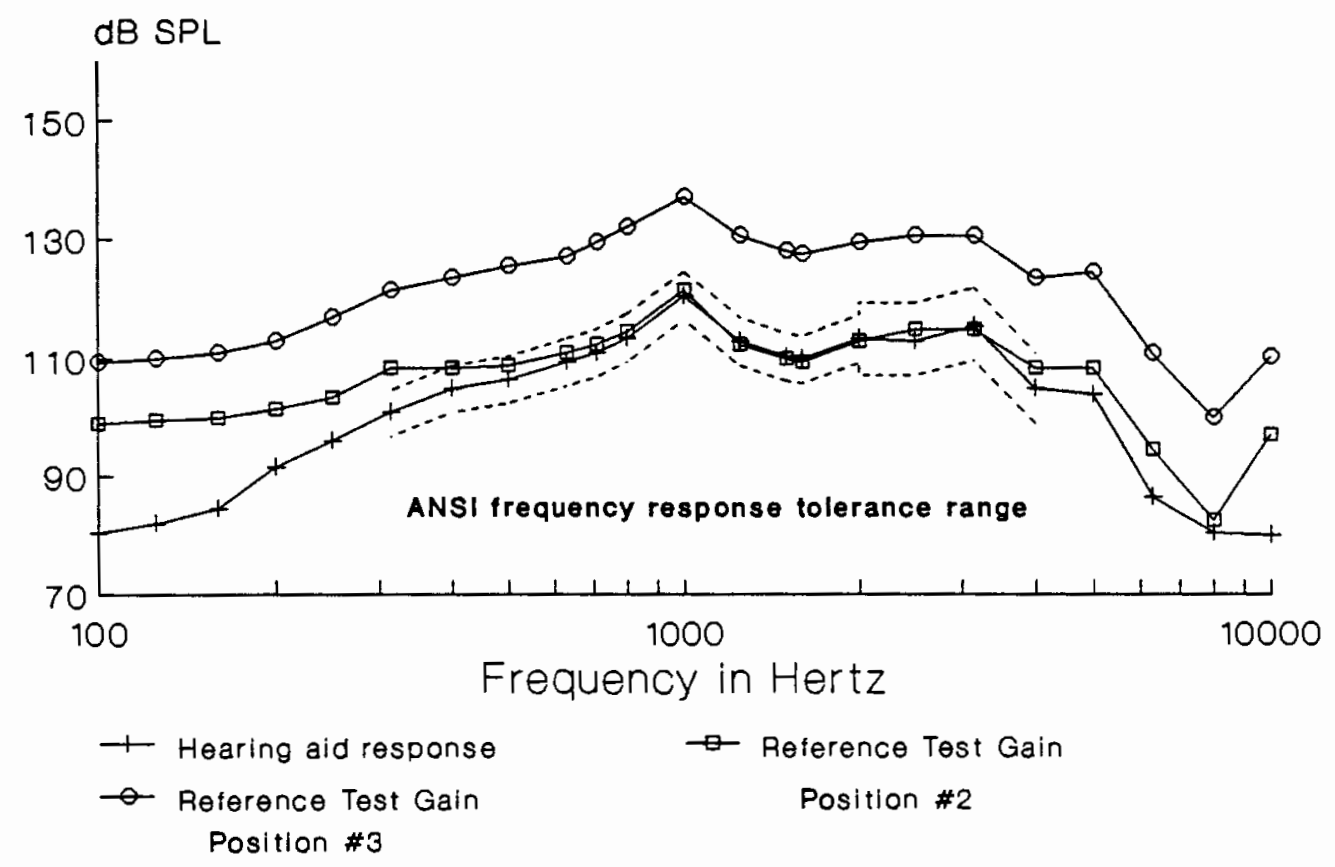

Figure 4. Frequency response curves for the UE 12 PPCL-A coupled using Direct Audio Input to the comtek Companion auditory trainer. Input level was set to $60 \mathrm{~dB}$ SPL. 
control set to 0 . This resulted in a frequency response curve which was $6.3 \mathrm{~dB}$ SPL higher in terms of average SPL as compared to the hearing aid-alone response (see Figure 4).

In order to summarize the tolerance data, the combined frequency response curves were placed into three categories; 1) inside the tolerance range without a template shift, 2) inside the tolerance range with a template shift, and 3) outside the tolerance range with the maximum template shift allowed by the standard (see Table III). Two out of the thirty-six combinations, or 5.5\% fell entirely within the tolerance range with no template shift. Twelve out of the thirty-six combinations, or nearly one third, fell within this range after the template shift. The most important finding was the large number, twenty-two out of thirty-six or $61.17 \%$, which failed to meet ANSI hearing aid tolerance requirements.

The following text describes the results of a similar table that placed this data into the same three categories grouped by Test condition (see Table IV).

\section{TEST CONDITIONS}

\section{Test condition \#1}

Under this condition, only one out of nine combinations, or $11.1 \%$, fell entirely within the tolerance range without a template shift. One out of nine, or $11.1 \%$ fell within this range with a template shift, and seven out 
of nine, or $77.8 \%$ failed to fall within these limits. This was the highest failure rate of all four Test conditions. Under this condition the Personal Mini-loop was used with Reference Test Gain Position \#2.

\section{TABLE III}

RESULTS OF FREQUENCY RESPONSE TOLERANCE ANALYSIS BY COMBINATION

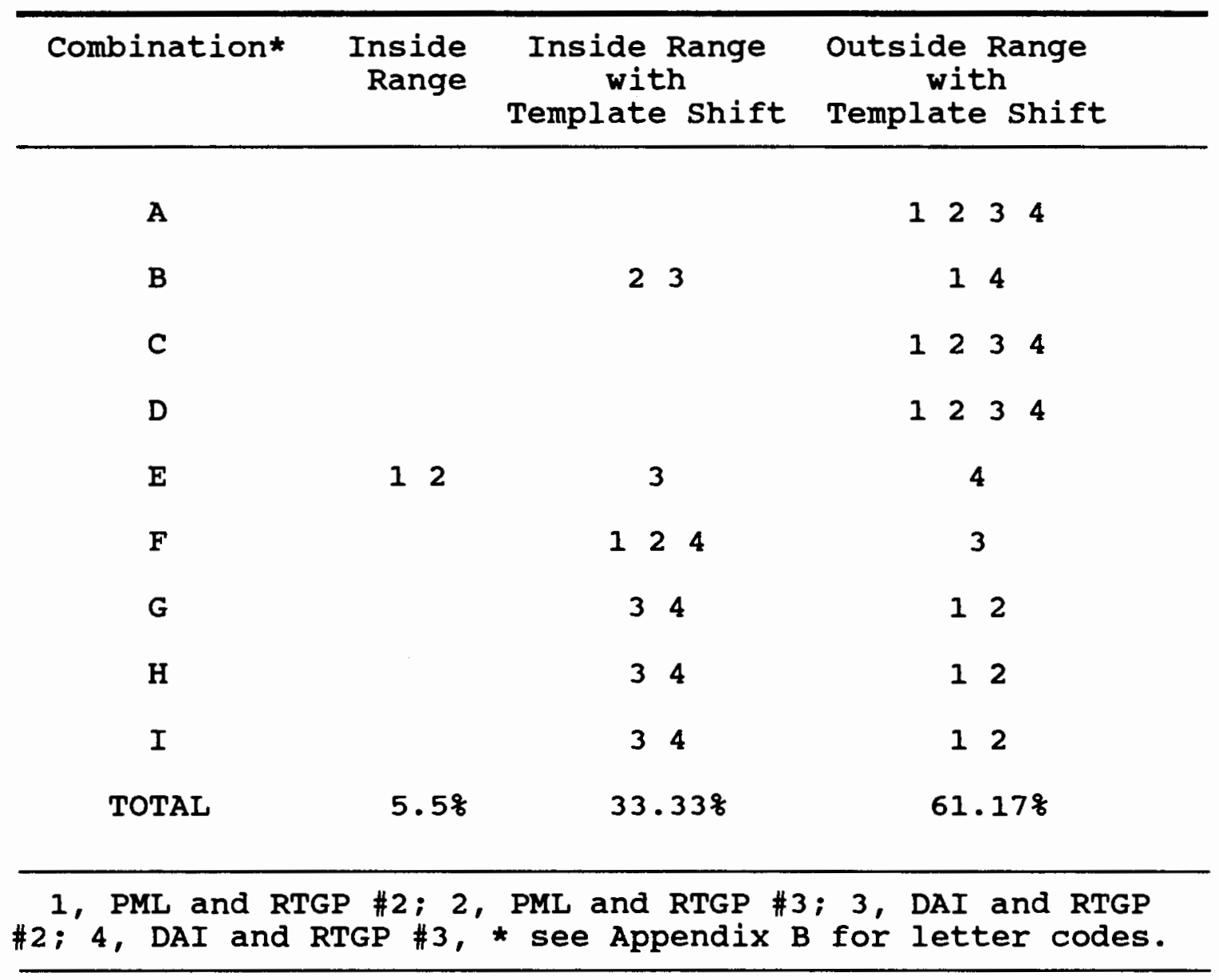

Test Condition \#2

Under this condition one out of nine, or 11.18 of the combinations fell within the tolerance range without a 
template shift. Two out of nine, or $22.2 \%$, fell within this range with a template shift, but six out of nine, or $66.17 \%$ failed. This condition combined the Personal Mini-loop with Reference Test Gain Position \#3.

The Personal Mini-loop coupling resulted in the only two frequency response curves which fell inside the tolerance range with no template shift, however, only one third of all these combinations met the ANSI frequency response tolerance specifications. A slightly greater number conformed to the ANSI tolerance specifications under Reference Test Gain Position \#3 than Reference Test Gain Position \#2 ( $33.3 \%$ vs. $22.2 \%)$.

\section{Test Condition \#3}

Under this condition none of the combinations met the ANSI tolerance specifications without a template shift. Five out of nine, or $55.6 \%$ did meet this standard with a template shift, but four out of the nine, or $44.4 \%$, failed. Many of the combinations that required a template shift to meet the standard required very little adjustment. This condition, which combined Direct Audio Input and Reference Test Gain Position \#2, yielded the highest proportion of combinations to meet this standard $(55.68)$.

\section{Test Condition \#4}

Like Test Condition \#3, none of these combinations met the ANSI standard without a template shift. Four out of 
nine, or 44.48 did fall within the ANSI standard with a template shift, but the remaining five out of nine, or 55.68, failed. This condition combined Direct Audio Input and Reference Test Gain Position \#3.

TABLE IV

RESULTS OF FREQUENCY RESPONSE TOLERANCE ANALYSIS BY TEST CONDITION

\begin{tabular}{cccc}
\hline $\begin{array}{c}\text { Test } \\
\text { Condition* }\end{array}$ & $\begin{array}{c}\text { Inside } \\
\text { Range }\end{array}$ & $\begin{array}{c}\text { Inside Range } \\
\text { with } \\
\text { Template Shift }\end{array}$ & $\begin{array}{c}\text { Outside Range } \\
\text { with } \\
\text { Template Shift }\end{array}$ \\
\hline \#1 & 11.18 & $11.1 \%$ & $77.8 \%$ \\
\#2 & $11.1 \%$ & $22.2 \%$ & $66.7 \%$ \\
PML Average & $11.1 \%$ & $16.6 \%$ & $72.3 \%$ \\
\hline \#3 & $0.0 \%$ & $55.6 \%$ & 44.48 \\
\#4 & $0.0 \%$ & $44.4 \%$ & 55.68 \\
DAI Average & $0.0 \%$ & $50.0 \%$ & 50.08 \\
\hline TOTAL & 5.58 & $33.33 \%$ & $61.17 \%$ \\
\hline 1, PML and RTGP \#2; 2, PML and RTGP \#3; 3, DAI and RTGP \\
\#2; DAI and RTGP \#3, * see Appendix B for number codes.
\end{tabular}

The two conditions using Direct Audio Input failed to produce a single frequency response curve that fell within the tolerance template without some adjustment, but $50 \%$ did meet the ANSI S3.22 (1982) standard. This is close to twice that found under the two Personal Mini-loop conditions $(27.7 \%)$. 
The use of percentages produces a gross picture of patterns which may be present in this data. To generate a more detailed view, frequency distribution graphs were constructed using all data points which fell outside the ANSI frequency response tolerance range after the template shift (see Figures 5 and 6 , Tables $V$ and VI). The frequency distributions were grouped by test condition.

Test Condition \#1 appears to have the worst performance with a mean decrease in output of $11.6 \mathrm{~dB}$ and the largest range of variation, $31.75 \mathrm{~dB}$. Test condition \#3 gave the best overall performance with a mean increase in mean low frequency output of $4.3 \mathrm{~dB}$, a standard deviation of 2.3 , and a range of $7.0 \mathrm{~dB}$.

\section{Statistical Analysis}

A three factor ANOVA was used to analyze the data. A three factor analysis of variance was performed on the mean high frequency output at 2,4 , and $8 \mathrm{kHz}$ to determine if there were any significant interactions between the conditions, the FM auditory trainers, and the hearing aids. The three factors were the four Test Conditions (Personal Mini-loop and Reference Test Gain Position \#2, Personal Mini-loop and Reference Test Gain Position \#3, Direct Audio Input and Reference Test Gain Position \#2, and Direct Audio Input and Reference Test Gain Position \#3), the three FM auditory trainers (Comtek Companion, Phonic Ear System 4, 


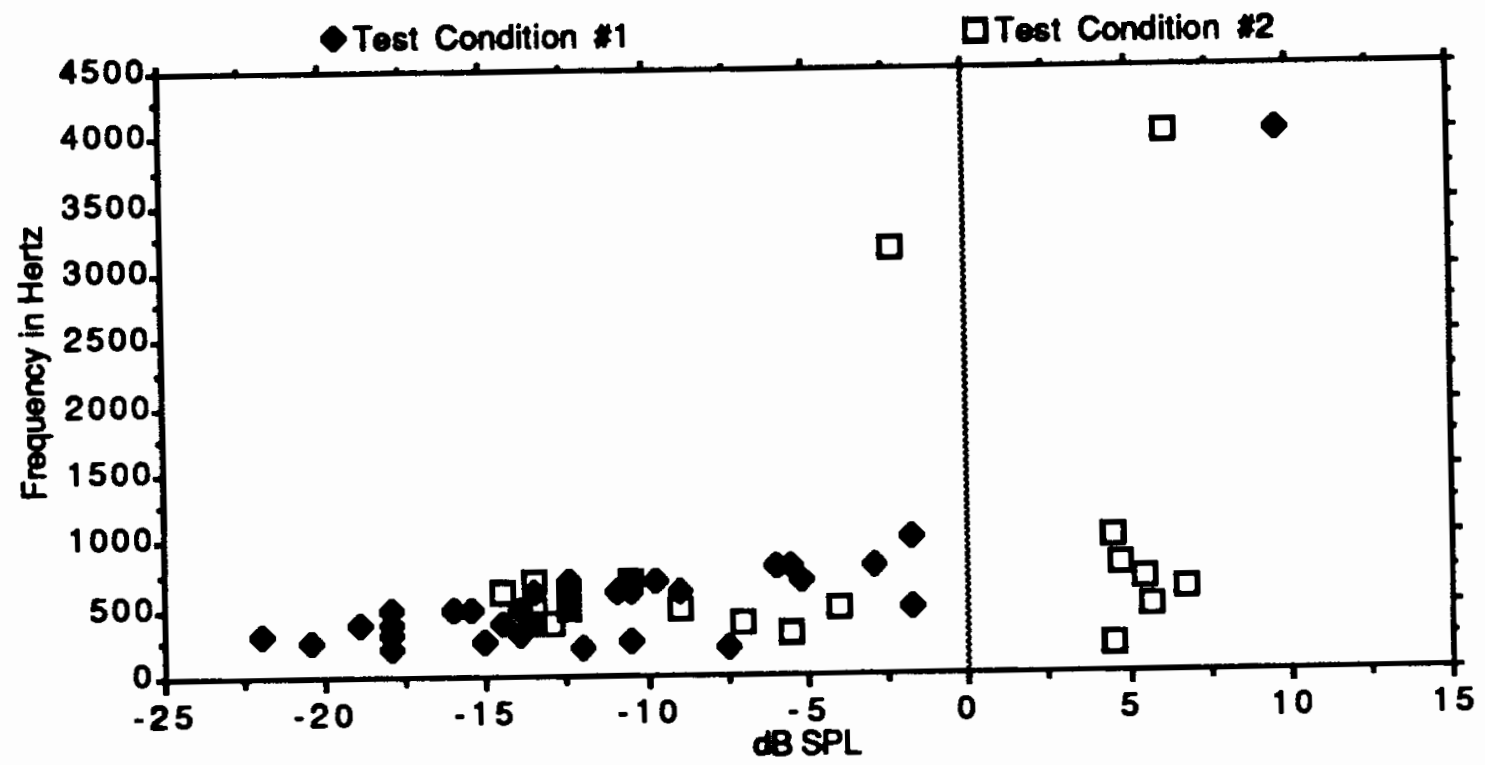

Fiqure 5. Frequency distribution for data points falling outside ANSI frequency response tolerance limits using Personal Mini-loop input. The tolerance templates were computed according to ANSI S3.22 19826.10 .1 and 6.10 .2 with input levels set at $60 \mathrm{~dB}$ SPL.

\section{TABLE V}

MEANS, STANDARD DEVIATIONS, AND RANGES OF DATA POINTS FALLING OUTSIDE ANSI FREQUENCY RESPONSE TOLERANCE LIMITS USING PERSONAL MINI-LOOP INPUT

\begin{tabular}{cccc}
\hline Test Condition & Mean* & S.D. & Range \\
\hline$\# 1$ & -11.6 & 6.2 & 31.75 \\
$\# 2$ & -4.7 & 8.3 & 21.25 \\
\hline
\end{tabular}

*All values in $\mathrm{dB}$ 


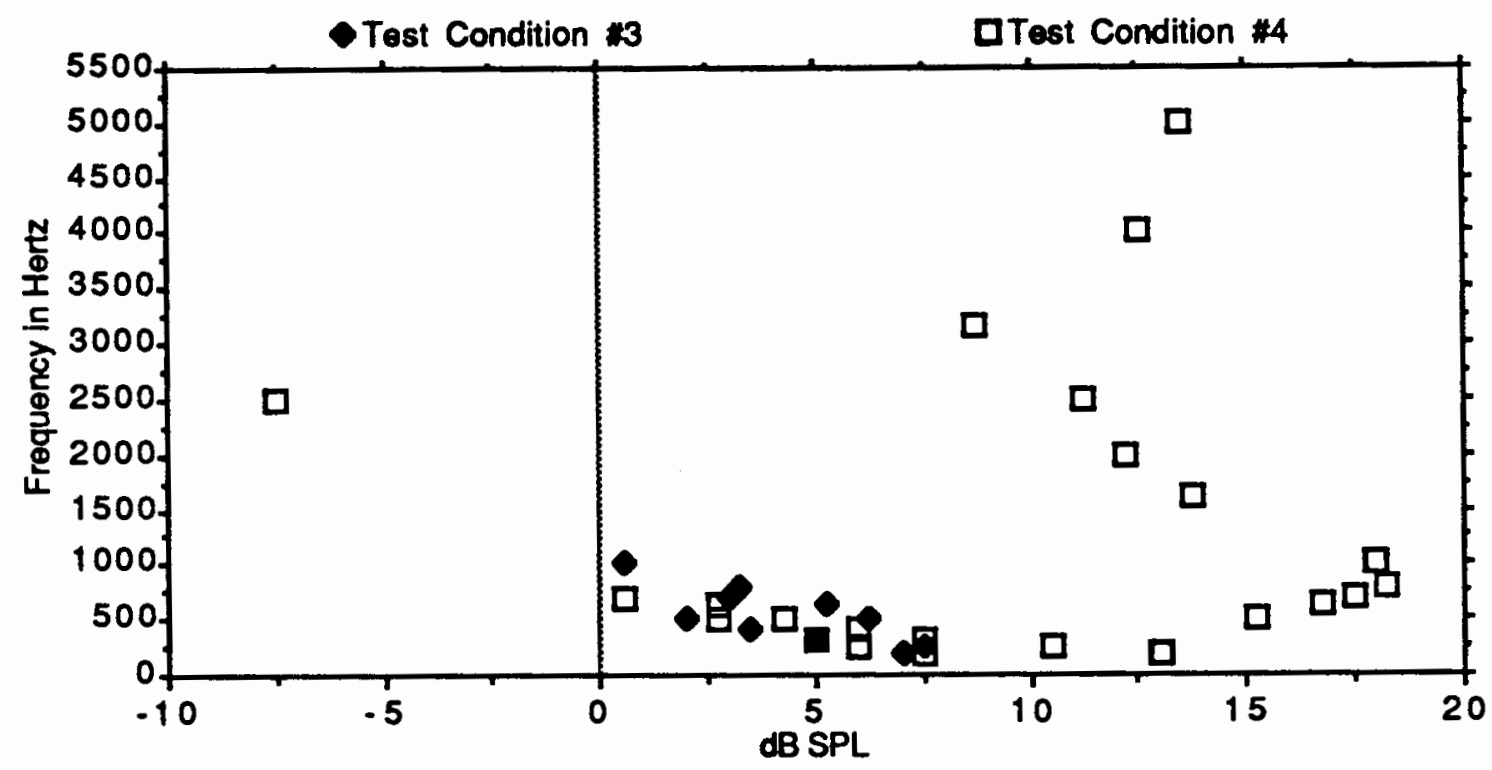

Figure 6. Frequency distribution for data points falling outside ANSI frequency response tolerance limits using Direct Audio Input. The tolerance templates were computed according to ANSI S3.22 19826.10 .1 and 6.10 .2 with input levels set at $60 \mathrm{~dB}$ SPL. Notice the small, tight cluster of points under Test Condition \#3.

\section{TABLE VI}

MEANS, STANDARD DEVIATIONS, AND RANGES OF DATA POINTS FALLING OUTSIDE ANSI FREQUENCY RESPONSE TOLERANCE LIMITS USING DIRECT AUDIO INPUT

\begin{tabular}{cccc}
\hline Test Condition & Mean* & S.D. & Range \\
\hline 3 & 4.3 & 2.3 & 7.0 \\
$\# 4$ & 9.4 & 6.4 & 25.7 \\
\hline
\end{tabular}

*All values in $\mathrm{dB}$ 
and Telex TDR-4) and the three hearing aids (PE 600 PPCH-A, Telex 372 L-A, and UE 12 PPCL-A).

No significant main effects, two way interactions, or three way interactions were present at the 0.05 level when mean high frequency output was used as the dependent variable (see Table VII). This result is not unusual given that all the combined frequency response curves were obtained according to the ANSI S3.22 (1982) procedure. This involves reducing the volume control setting until the high frequency average of $1,1.6$, and $2.5 \mathrm{kHz}$ with a $60 \mathrm{~dB}$ SPL is equal to the same high frequency average minus $17 \mathrm{~dB} \pm 1 \mathrm{~dB}$ with a $90 \mathrm{~dB}$ SPL input. Since there was little variation in the high frequency average with a $90 \mathrm{~dB}$ SPL input between the hearing aid-alone response and the combined response, these values remained relatively constant between all the combinations under the four test conditions. The excessive variability reflected in the large value of 221.3 for the error of the mean square may be a result of difficulties in matching these averages using some combinations which were grossly incompatible.

A three factor analysis of variance was performed on the mean low frequency output at $125,250,500$, and $1000 \mathrm{~Hz}$ to determine if there were any significant interactions between the conditions, the FM auditory trainers, and the hearing aids. Significant main effects were observed at the 0.0001 level for test conditions. Significant main effects 
were observed at the 0.01 level for FM auditory trainers. No significant main effects were observed for hearing aids at the 0.05 level. None of the two or three way interactions were significant at the 0.05 level (see Table VIII).

A one factor ANOVA and Multiple Comparison test was performed between and within the groups for mean low frequency output of the test conditions. The findings are summarized in Table IX below. The F-values indicate that the mean low frequency output of Test Conditions \#1 vs. \#3, \#I vs. \#4, and \#2 vs. \#4 differ significantly at the 0.05 level.

\section{TABLE VII}

RESULTS OF THREE FACTOR ANOVA FOR COMPARISON OF MEAN HIGH FREQUENCY OUTPUT BETWEEN TEST CONDITIONS FM AUDITORY TRAINERS, AND HEARING AIDS

\begin{tabular}{ccccc}
$\begin{array}{c}\text { Source of } \\
\text { Variation }\end{array}$ & $\begin{array}{c}\text { Degrees of } \\
\text { Freedom }\end{array}$ & $\begin{array}{c}\text { Sum of } \\
\text { Squares }\end{array}$ & $\begin{array}{c}\text { Mean } \\
\text { Square }\end{array}$ & F-test \\
\hline Test Condition (A) & 3 & 948.5 & 316.0 & $1.43^{\mathrm{a}}$ \\
$\begin{array}{c}\text { FM Auditory } \\
\text { Trainer (B) }\end{array}$ & 2 & 219.6 & 109.8 & $0.49^{\mathrm{a}}$ \\
Hearing Aid (C) & 2 & 429.4 & 214.7 & $0.97^{\mathrm{a}}$ \\
AB & 6 & 358.6 & 59.8 & $0.27^{\mathrm{a}}$ \\
AC & 6 & 208.9 & 34.8 & $0.16^{\mathrm{a}}$ \\
BC & 4 & 41.6 & 10.4 & $0.05^{\mathrm{a}}$ \\
ABC & 12 & 271.0 & 22.6 & $0.10^{\mathrm{a}}$ \\
ERROR & 72 & 15935.5 & 221.3 & \\
\hline
\end{tabular}

a Not significant at the 0.05 level. 
The difference in mean low frequency output between these three groups ranged from $-11.2 \mathrm{~dB}$ SPL to $-17.2 \mathrm{~dB}$ SPL. None of the multiple comparisons between FM Auditory Trainers were significant at the 0.05 level when evaluated using the Scheffe F-test (Winer, 1971). However, when the Fischer PLSD (Winer, 1971) test was used the comparison between the comtek Companion and Phonic Ear System 4 was significant at the 0.05 level.

\section{TABLE VIII}

RESULTS OF THREE FACTOR ANOVA FOR COMPARISON OF MEAN LOW FREQUENCY OUTPUT BETWEEN TEST CONDITIONS FM AUDITORY TRAINERS, AND HEARING AIDS

\begin{tabular}{ccccc}
$\begin{array}{c}\text { Source of } \\
\text { Variation }\end{array}$ & $\begin{array}{c}\text { Degrees of } \\
\text { Freedom }\end{array}$ & $\begin{array}{c}\text { Sum of } \\
\text { Squares }\end{array}$ & $\begin{array}{c}\text { Mean } \\
\text { Square }\end{array}$ & F-test \\
\hline $\begin{array}{c}\text { Test condition (A) } \\
\text { FM Auditory } \\
\text { Trainer (B) }\end{array}$ & 3 & 6045.8 & 2015.3 & $16.97^{\mathrm{b}}$ \\
Hearing Aid (C) & 2 & 966.8 & 483.4 & $4.07^{\mathrm{c}}$ \\
AB & 2 & 571.4 & 285.7 & $2.40^{\mathrm{a}}$ \\
AC & 6 & 664.8 & 110.8 & $0.93^{\mathrm{a}}$ \\
BC & 6 & 753.8 & 125.6 & $1.06^{\mathrm{a}}$ \\
ABC & 4 & 162.8 & 40.7 & $0.34^{\mathrm{a}}$ \\
ERROR & 12 & 618.6 & 51.6 & $0.43^{\mathrm{a}}$ \\
\hline
\end{tabular}

a Not significant at the 0.05 level.

b Significant at the 0.0001 level.

c Significant at the 0.01 level. 
The Fischer PLSD test is only included here to account for the discrepancy in the significance levels between and within the groups. The ANOVA between groups yielded a $p$ of 0.046 , just under the 0.05 level. Within groups none of the multiple comparisons were significant at the 0.05 level using the scheffe F-test. The comparison between the comtek Companion and the Phonic Ear System 4 auditory trainers was significant at the 0.05 level using the Fischer PLSD test. This may be because the scheffe F-test is more conservative as compared to the Fischer PLSD test (winer, 1971).

TABLE IX

RESULTS OF ONE FACTOR ANOVA AND MULTIPLE COMPARISON TESTS ON MEAN LOW FREQUENCY OUTPUT

BETWEEN TEST CONDITIONS

\begin{tabular}{|c|c|c|c|c|c|}
\hline $\begin{array}{l}\text { Source of } \\
\text { Variation }\end{array}$ & \multicolumn{2}{|c|}{$\begin{array}{c}\text { Degrees of } \\
\text { Freedom }\end{array}$} & $\begin{array}{l}\text { Sum of } \\
\text { Squares }\end{array}$ & $\begin{array}{c}\text { Mean } \\
\text { Square }\end{array}$ & F-test \\
\hline \multicolumn{6}{|c|}{ TEST CONDITIONS } \\
\hline Between Groups & & 3 & 6045.8 & 2015.3 & 17.0 \\
\hline within Groups & & 140 & 16564.9 & 118.3 & $p=0.0001$ \\
\hline Total & & 143 & 22610.7 & & \\
\hline Comparison & Mean & Differenc & ce & cheffe $F$ - & -test \\
\hline 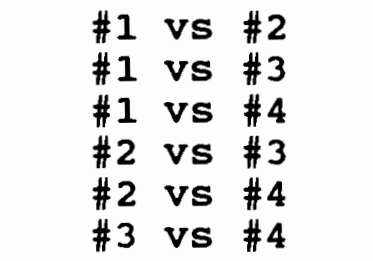 & & $\begin{array}{r}-5.0 \\
-11.2 \\
-17.2 \\
-6.2 \\
-12.2 \\
-6.0\end{array}$ & & $\begin{array}{l}1.3 \\
6.4^{\star} \\
15.1 * \\
1.9 \\
7.5 * \\
1.8\end{array}$ & \\
\hline
\end{tabular}

*Significant at 0.05 
In this limited sample of hearing aids and FM auditory trainers, it appears that the test condition is the variable which significantly influences mean low frequency response. The method used to interface these devices and the volume control settings used are the primary factors that determine whether the combined frequency response characteristics of an FM auditory trainer and hearing aid will differ significantly from that of the hearing aid-alone.

\section{TABLE $X$}

RESULTS OF ONE FACTOR ANOVA AND MULTIPLE COMPARISON TESTS ON MEAN LOW FREQUENCY OUTPUT BETWEEN FM AUDITORY TRAINERS

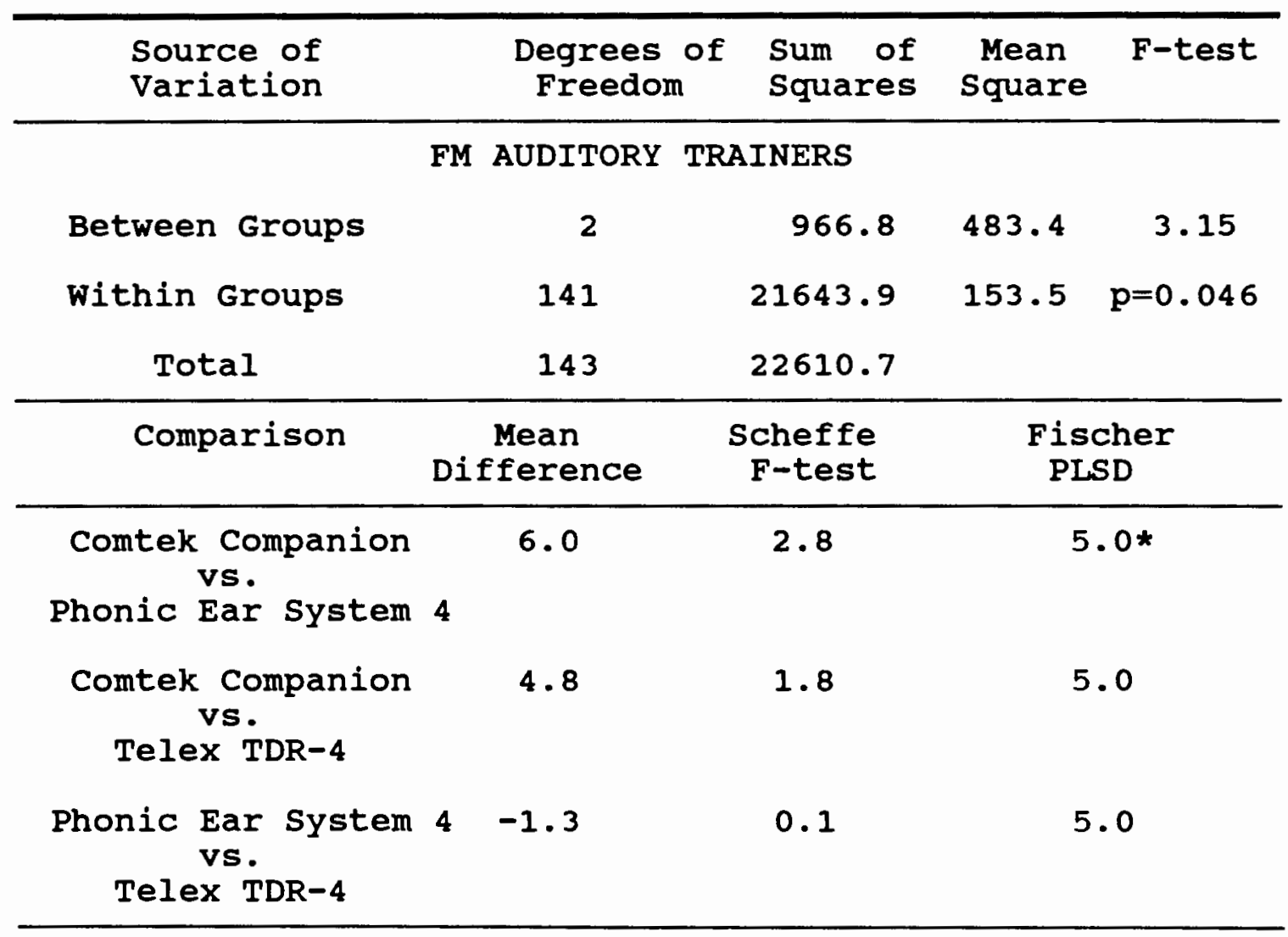




\section{CHAPTER V}

\section{DISCUSSION}

In this experiment, frequency response curves were collected from three hearing aids while individually coupled with the three FM auditory trainers using either a Direct Audio Input cord or a Personal Mini-loop. This tested the entire system simultaneously, as if it were a single hearing aid with the microphone and receiver linked by FM radio waves. The present study investigated the effect of two coupling methods, two volume control settings, and the interactive effects of three hearing aids combined with three FM auditory trainers on the frequency response of the combined systems as compared to the frequency response of the same hearing aids measured without the FM auditory trainers. These results were analyzed statistically, and descriptively in terms of the frequency response tolerance specifications for hearing aids contained in ANSI S3.22 (1982).

This study examined the frequency response changes associated with two different coupling methods, two different volume control settings and nine different combinations of three hearing aids and three FM auditory trainers. Significant changes in output were found for the 
low frequency band $(125,250,500$, and $1000 \mathrm{~Hz})$ which were dependent on the coupling method. The Personal Mini-loop tended to produce significant reductions in low frequency output as compared to the hearing aid-alone response. The use of Direct Audio Input tended to produce smaller, but still significant increases in low frequency output. This method produced the best overall agreement with the hearing aid frequency response, especially when the FM auditory trainer was set at full-on gain and the hearing aid at a low gain setting.

These results are consistent with those of Van Tassel and Landin (1980). The combinations using Personal Mini-loop produced the largest percentage (72.38) of combinations that fell outside ANSI frequency response tolerance standards. Test conditions \#1, which employed the Personal Mini-loop, resulted in the largest mean, standard deviation, and range for frequencies falling outside the ANSI tolerance range (see Table V). Van Tassel and Landin (1980) reported that the frequency response of hearing aids changed unpredictably when the aids were coupled to an FM auditory trainer using a Personal Mini-loop. Their study investigated five FM auditory trainers coupled with one hearing aid using Personal Mini-loop input at only one volume control setting. A total of five combinations represents a rather small sample size to conclude that the frequency response of the hearing aids coupled with FM auditory trainers using 
Personal Mini-loops differ unpredictably from the frequency responses of the hearing aids measured alone.

The results of the present study support Hawkins and Van Tassels' findings that less variability was observed in the Direct Audio Input responses as compared to the Personal Mini-loop responses. Hawkins and Van Tassel (1982) investigated the electroacoustic characteristics of four hearing aids interfaced using Personal Mini-loop and Direct Audio Input with one FM auditory trainer. They reported large variability in the frequency responses of hearing aids coupled using Personal Mini-loop input to FM auditory trainers as compared to the microphone responses of the same hearing aids. Only minor differences were observed when hearing aids and FM auditory trainers were coupled using Direct Audio Input. These results may be questionable due to the small sample size. Only one FM auditory trainer hearing aid combination was measured using Direct Audio Input and two FM auditory trainers in combination with a different hearing aid were measured using the Personal Mini-loop. Hawkins and Schum (1985) investigated the frequency responses of four different hearing aids coupled with two different FM auditory trainers using Direct Audio Input and Personal Mini-loop input (as well as some variables unrelated to the present study). Large differences were observed between some frequency response comparisons, with equally poor results obtained using both coupling methods. 
Their conclusion that it cannot be assumed that the frequency response characteristics of a hearing aid are preserved using either of these methods may have been premature due to their small sample size. Only four hearing aids in combination with two FM auditory trainers and only six of the eight possible combinations were used in the final analysis. The results of the present study contradict this conclusion since they suggest that Direct Audio Input is superior to the Personal Mini-loop.

Another limitation of Hawkins and Schum (1985) is the higher input level ( $84 \mathrm{~dB}$ SPL) that was used at the FM microphone during testing of Direct Audio Input and Personal Mini-loop responses. This was compared to the hearing aid microphone responses obtained using an input of $60 \mathrm{~dB}$ SPL. This may have introduced some measurement error since it assumes that the frequency response of the hearing aid remains the same at both input levels. Although the input level of $84 \mathrm{~dB}$ SPL may better approximate the actual input to the FM microphone, this causes an inconsistency between the two test conditions. This could have been controlled by measuring both response with an input at 84 dB SPL.

In the absence of any standard for the measurement of the electroacoustic characteristic of FM auditory trainers when used in conjunction with hearing aids, previous investigators have had to invent their own. Hawkins and Van Tassel (1982) and Hawkins and Schum (1985) both used 
'Equivalent $1 \mathrm{kHz}$ Gain Position' (E1KGP) to set the volume control of the FM auditory trainer while coupled with the hearing aid. This is defined as the FM receiver volume control setting which yields the same sound pressure level at $1 \mathrm{kHz}$ when interfaced with a hearing aid set at reference test gain position as the hearing aid-alone set at reference test gain position. This results in two frequency response curves which intersect at $1 \mathrm{kHz}$, which means that there may be variations in frequency response above or below $1 \mathrm{kHz}$. All frequency responses are measured using a $60 \mathrm{~dB}$ SPL input under E1KGP conditions. Hawkins and Schum (1985) used 60 and $84 \mathrm{~dB}$ SPL input levels together with ElKGP settings, which may have introduced a certain amount of measurement error to their results.

In the present study the high frequency average of $1.0,1.6$, and $2.5 \mathrm{kHz}$ was used to set the volume controls for the frequency response measurements. Adequate sound energy in the high frequency region from 2 to $6 \mathrm{kHz}$ is crucial for speech discrimination, especially the unvoiced consonants. If one set the combined system so that the high frequency average was the same as for the hearing aid-alone, then the low frequency region could be adjusted to bring it back within the ANSI tolerance range. This would be best accomplished by means of a low cut filter built into the FM auditory trainer. This would eliminate the need to 
constantly reset the low cut control on the hearing aid every time it was used with one of these systems. Since the ANSI S3.22 (1982) standard was used to analyze the combined frequency responses, it seemed appropriate to set the volume controls using the high frequency average since the tolerance range is divided into the low and high frequency regions at $2.0 \mathrm{kHz}$.

In the previous studies, the hearing aid and FM auditory trainer were treated as separate components. To a certain extent this approach is justified by the need to isolate the variables in any systematic study. When examined on an electrical level this separation breaks down. An FM auditory trainer coupled to a hearing aid using direct audio input or personal mini-loop input may behave like two amplifiers in a series. Many amplifiers consist of more than one stage built into a single circuit, thus the combined FM auditory trainer and hearing aid may be evaluated as a single two staged amplifier with a gain control potentiometer for each stage. Testing the combined system with the first stage set at maximum gain while adjusting the second stage to the combined reference test gain position should reveal the maximum changes in frequency response curves. This process was reversed with the second stage set at maximum gain and the first adjusted to the combined reference test gain position. This tested the 
combined systems at gain control settings where any nonlinearity in the frequency response would be most probable. The number of combinations of hearing aids and FM auditory trainers has been relatively restricted in previous studies. In most of these studies all possible combinations of the units under investigation were not examined, possibly due to an inability to interconnect the units. In the present study, all possible combinations of the hearing aids, FM auditory trainers, and coupling methods under investigation were examined. This allowed a statistical analysis which revealed which factors significantly affected frequency response. None of the prior studies have investigated in a systematic manner the interaction of the hearing aid, FM system, coupling method, and volume control setting on frequency response.

In this study the use of Direct Audio Input resulted in the smallest amount of change in frequency response as compared to the control, or hearing aid-alone frequency response. Although none of the Direct Audio Input combinations fell entirely within the ANSI tolerance range without a template shift, this coupling method did produce the largest percentage of combinations to meet the standard with a template shift (50\%). A slightly higher percentage of these were under the Reference Test Gain Position \#2 condition as compared to the Reference Test Gain Position \#3 condition ( $55.6 \%$ vs. $44.4 \%$ ). The multiple comparison between 
the two Direct Audio Input combinations revealed the difference was not significant at the 0.05 level. The testretest reliability appeared to be excellent, with repeated measurements on hearing aid and FM Auditory Trainer combinations varying by a mean of $\pm 1.53 \mathrm{~dB}$ SPL.

The mean low frequency output of Test condition \#1 was significantly different from Test conditions \#3 and \#4 at the 0.05 level. Under Test condition \#1 thirty-six data points fell outside the ANSI tolerance range, ranging from -22 to $9.75 \mathrm{~dB}$. Test conditions \#3 and \#4 had only 10 and 23 data points outside the tolerance limits, ranging from 0.5 to 7.5 and -7.5 to $18.25 \mathrm{~dB}$, with mean values of 4.3 and 9.4 $d B$, respectively. It appears that the use of the Personal Mini-loop causes a significant decrease in low frequency output, especially when the FM auditory trainer is set at a high gain level and the hearing aid is set at a low level. This could cause serious problems for a hearing impaired student who requires a low frequency emphasis hearing aid. This student may be more likely to increase the hearing aid gain setting to compensate for this and in the process may saturate his hearing aid in the high frequency region. This would result in peak clipping which would greatly increase harmonic distortion, further degrading the speech signal and perhaps resulting in decreased word discrimination ability. The mean low frequency output of Test Condition \#2 was significantly different from Test condition \#4 at the 0.05 
level. Under Test condition \#2, twenty data points fell outside the ANSI tolerance range, ranging from -14.5 to 6.75 $\mathrm{dB}$, with a mean of $-4.7 \mathrm{~dB}$. Test condition \#4 had more data points falling outside the tolerance range, these values ranged from -7.5 to $18.25 \mathrm{~dB}$ with a mean of $9.4 \mathrm{~dB}$. Test Condition \#2 did not differ significantly from Test Condition \#3, probably because the mean difference was so small, $-6.2 \mathrm{~dB}$.

These results indicate that when the two Personal Mini-loop Test Conditions are compared to each other no significant difference is found at the 0.05 level (Test Conditions \#1 vs \#2). The same holds true for the two Direct Audio Input Test Conditions (\#3 and \#4). This result indicates that the variable primarily responsible for altering the frequency response from the hearing aid-alone response is the method used to couple the hearing aid to the FM auditory trainer.

It appears that Direct Audio Input is the coupling method that produces the least amount of change in the frequency response of hearing aids when coupled with FM auditory trainers. It also appears that it is best to set the FM auditory trainer volume control to a high level and the hearing aid volume control to a low level using this coupling method. This resulted in the smallest mean, standard deviation, and range for frequency points falling outside the ANSI tolerance range. 
In this study the effects of three independent variables on the frequency responses of three hearing aids have been examined. One must apply these results with caution, however, since they only apply to the rather limited sample of hearing aids and FM auditory trainers used in the present study. Although general recommendations have been made from these results, they may be totally inappropriate when applied to a different sample of hearing aids combined with FM auditory trainers. It is the electrical engineer that designs these systems who is ultimately responsible for their compatibility when interfaced with hearing aids, but electrical engineers do not fit these systems to the end users. Therefore, the ultimate responsibility lies with the audiologist.

More research remains to be done in this area. The effects of various combinations of hearing aids and FM auditory trainers on variables other than frequency response should be examined. What is the optimum combination of volume control settings necessary to minimize total harmonic distortion? How can these systems be engineered to reduce the levels of noise generated by the circuitry and radio static? Also, due to the need for improved signal clarity and more versatile auditory training systems, immediate attention should be placed on developing infrared and digital radio frequency based systems. 
It would be of added benefit to the hearing impaired child if every auditory trainer was extensively analyzed in combination with the user's hearing aid to determine if the units are electroacoustically compatible. It would certainly be the best practice to measure all combined systems using real ear measurements to insure against overamplification, and the double threats of upward spread of masking and the possibility of causing further hearing loss.

In certain instances some of the combinations may result in severe saturation of the hearing aid. It would be prudent to recommend against combining these units because of a basic electrical incompatibility. It might be useful to look at other combinations of hearing aids and auditory trainers in future investigations. It would be appropriate to recommend Direct Audio Input over the Personal Mini-loop as a coupling method since Direct Audio Input caused the least amount of change in the combined frequency response. However, Direct Audio Input did cause an increase in low frequency output which could result in an upward spread of masking when combined with the high levels of ambient noise present in most classroom environments. At present this information could be applied by classroom teachers, school speech pathologists, or district educational audiologists. Finally, this investigator is of the opinion that digital based, full multiplex auditory training devices will be of great benefit to hearing impaired children in the 
educational systems of the near future. These systems will have multiband, active equalization built in, which will allow the audiologist to fine tune the frequency response of the combined system to exactly duplicate that of the hearing aid-alone. 


\section{REFERENCES CITED}

American National Standards Institute (1982). American National standard for Hearing Aid Characteristics S3.22 6.10.1, and 6.10.2. New York: American National Standards Institute.

Burgess, V. R. (1975). A new system for wireless linked auditory trainers and hearing aids. THE AUSTRALIAN TEACHER OF THE DEAF, 16,26 .

Burgess, V. R., Christen, R., Donald, G. \& Lowe, A. (1979). Radio frequency hearing aids: the need for complementary and compatible channel allocation. THE VOLTA REVIEW, 81, 91-99.

Byrne, D. \& Christen, R. (1981). Providing an optimal auditory signal with varied communication systems. In F. Bess, B. Freeman \& J. Sinclair. (Eds.), Amplification in Education (pp. 286-304). Washington, DC: A. G. Bell Association.

Crum, M. \& Matkin, N. (1976). Room acoustics: the forgotten variable. LANGUAGE, SPEECH, AND HEARING SERVICES IN SCHOOLS, 7, 106-110.

Finitzo-Heiber, T. \& Tillman, T. W. (1978). Room acoustics effects on monosyllabic word discrimination ability for normal and hearing-impaired children. JOURNAL OF SPEECH AND HEARING DISORDERS, 21, 440-458.

Freeman, B. A., Sinclair, J. S. \& Riggs, D. E. (1980). Electroacoustic performance characteristics of FM auditory trainers. JOURNAL OF SPEECH AND HEARING DISORDERS, 45, 16-26.

Giolas, T. \& Epstein, A. (1963). Comparative intelligibility of word lists and continuous discourse. JOURNAL OF SPEECH AND HEARING RESEARCH, 6, 349-358.

Hawkins, D. B. (1984). Comparisons of speech recognition in noise by mildly-to-moderately hearing-impaired children using hearing aids and FM systems. JOURNAL OF SPEECH AND HEARING DISORDERS, 49, 409-418.

Hawkins, D. B. \& Schum, D. J. (1985). Some effects of FM-system coupling on hearing aid characteristics. JOURNAL OF SPEECH AND HEARING DISORDERS, 50, 132-141. 
Hawkins, D. B. \& Van Tassel, D. J. (1982). Electroacoustic characteristics of personal FM systems. JOURNAL OF SPEECH AND HEARING DISORDERS, 47, 355-362.

Hodgson, w. R. \& Sung, R. J. (1972). Comparative performance of hearing aid microphone and induction coil for a sentence intelligibility test. JOURNAL OF AUDITORY RESEARCH, 12, 261-264.

International Electrotechnical Commission (1976). Recommended methods for measurement of hearing aid equipment not worn on the person. DRAFT SUPPLEMENT TO IEC PUBLICATION, 118, 31-33.

Matkin, N. \& Olsen, W. (1973). An investigation of radio frequency auditory training units. AMERICAN ANNALS OF THE DEAF, 118, 25-30.

Nabelek, A. K. \& Donahue, A. M. (1986). Comparison of amplification systems in an auditorium. JOURNAL OF THE ACOUSTICAL SOCIETY OF AMERICA, 79, 2078-2082.

Nabelek, A. K., Donahue, A. M. \& Letowski, T. R. (1986). Comparison of amplification systems in a classroom. JOURNAL OF REHABILITATION RESEARCH AND DEVELOPMENT, 23 no.1, 41-52.

Newby, H. A.\& Popelka, G. R. (1985). Audiology (5th ed.). New York: Prentice-Hall, Inc..

Picard, M. \& Lefrancois, J. (1986). Speech perception through FM auditory trainers in noise and reverberation. JOURNAL OF REHABILITATION RESEARCH AND DEVELOPMENT, 23 no.1, 53-62.

Pollack, D. (1989). Educational audiology for the limited hearing infant. (Springfield: Charles C. Thomas, Publisher.

Roeser, R.\& Downs, M. P. (1981). Auditory disorders in school children. (New York: Liene-stratton.

Saunders, D. A. (1971). Aural Rehabilitation. (Englewood Cliffs: Prentice-Hall, Inc..

sung, G. S., Sung, R. J., Hodgson, W. R. \& Angelelli, R. M. (1976). Performance of hearing aids with an induction loop amplification system: Laboratory vs. classroom setting. AUDIOLOGY, 15, 249-256. 
Sung, R. J. \& Hodgson, W. B. (1971). Performance of individual hearing aids utilizing microphone and induction coil input. JOURNAL OF SPEECH AND HEARING RESEARCH, $14,365-371$.

Van Tassel, D. J. \& Landin, D. P. (1980). Frequency response characteristics of FM mini-loop auditory trainers. JOURNAL OF SPEECH AND HEARING DISORDERS, XLV, 247-258.

Van Tassel, D. J., Mallinger, C. A. \& Crump, E. S. (1986). Functional gain and speech recognition with two types of FM amplification. IANGUAGE, SPEECH, AND HEARING SERVICES IN SCHOOLS, 17, 28-37.

Vargo, S. W., Taylor, G., Tannahill, J. C. \& Plummer, S. A. (1970). The intelligibility of speech by hearing aids on inductance loop and microphone modes of signal reception. JOURNAL OF SPEECH AND HEARING RESEARCH, 13, 82-86.

winer, B. (1971). Statistical principles in experimental design (2nd ed.). New York: McGraw-Hill. 


\section{APPENDIX A}

FREQUENCY RESPONSE GRAPHS OBTAINED USING THE TOLERANCE METHOD FOR THE FREQUENCY RESPONSE CURVES

OF HEARING AIDS (ANSI S3.22 1982

$$
6.10 .1,6.10 .2 \text { ) }
$$




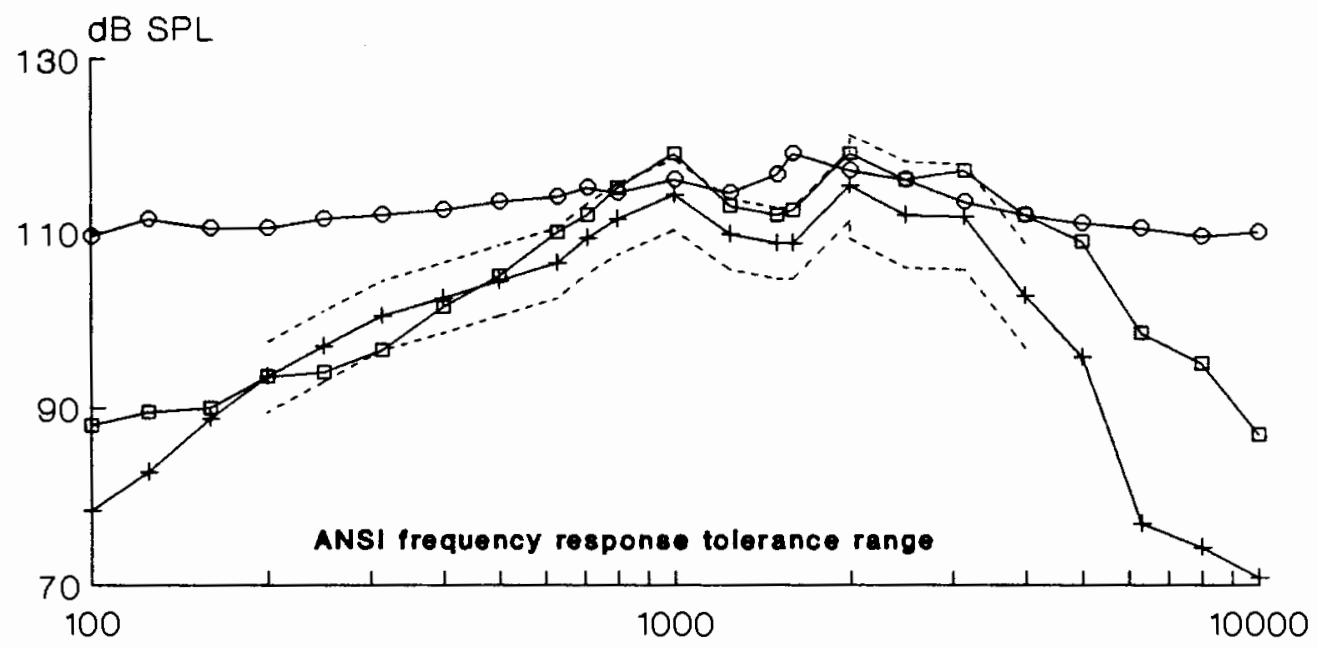

Frequency in Hertz
- Hearing aid response $\rightarrow$ Reference Test Gain.
- Reference Test Gain Position \#2 Position \#3

Telex 372 L-A coupled using Personal Mini-loop to the Comtek Companion. Input level set at $60 \mathrm{~dB}$ SPL.

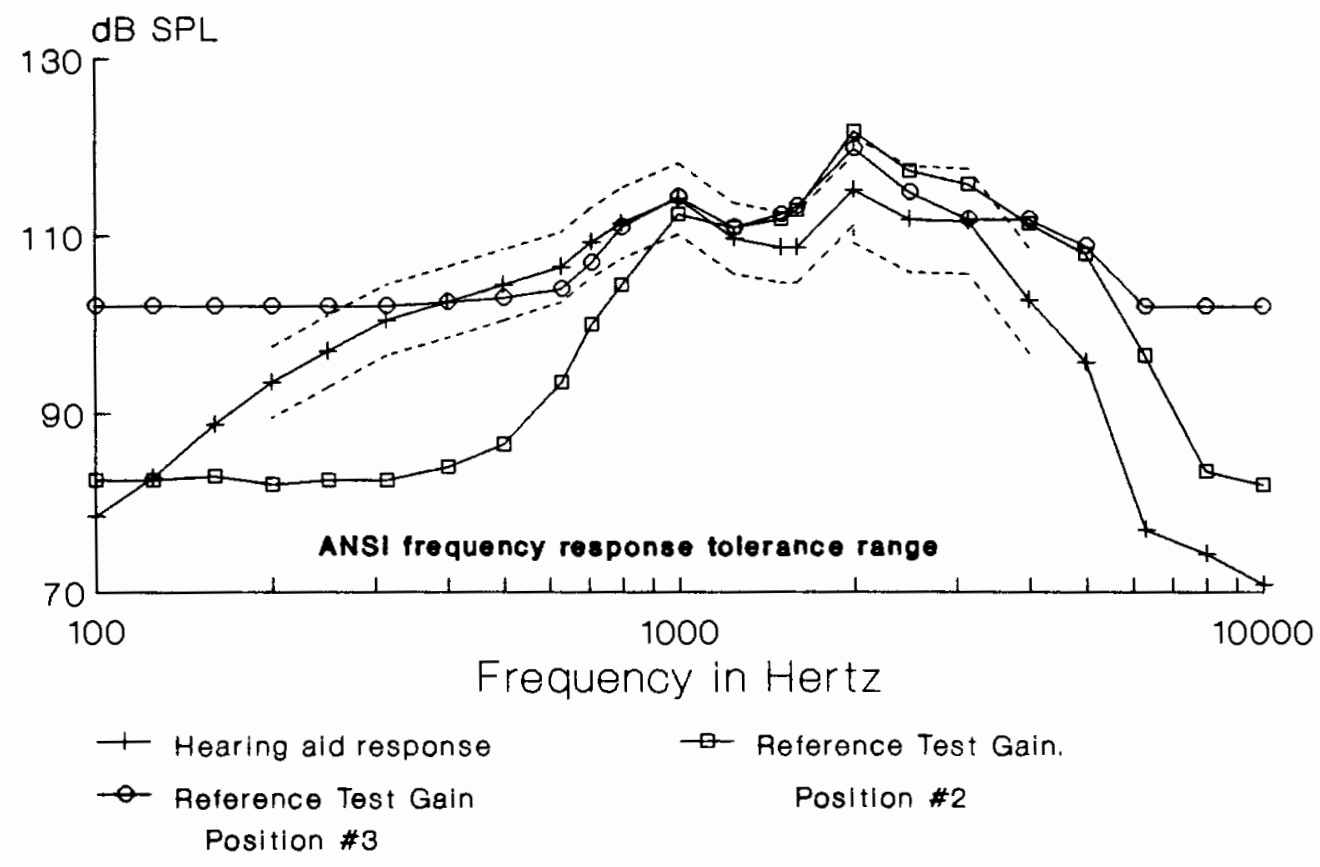

Telex 372 L-A coupled using Direct Audio Input with the comtek Companion. Input level set at $60 \mathrm{~dB}$ SPL. 


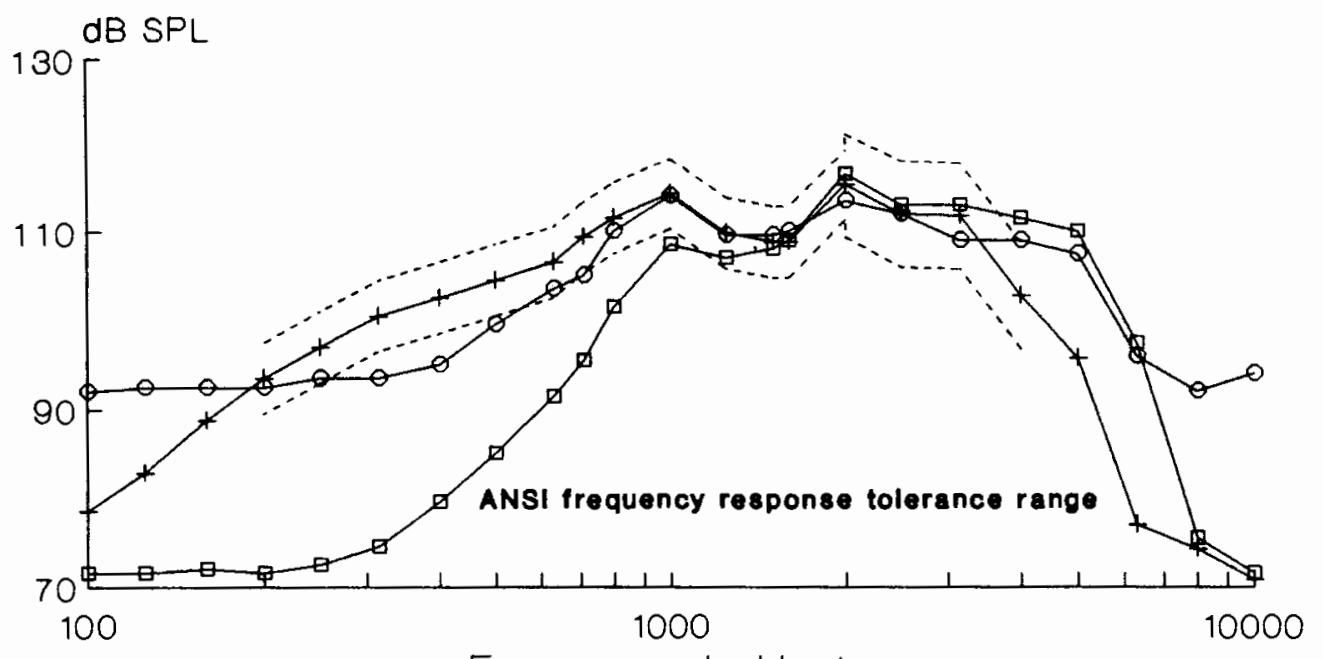

Frequency in Hertz
- Hearing ald response $\rightarrow-$ Reterence Test Gain.
- Relerence Test Gain Position \#2 Position \#3

Telex 372 L-A coupled using Personal Mini-loop to the Phonic Ear System 4. Input level set at $60 \mathrm{~dB}$ SPL.

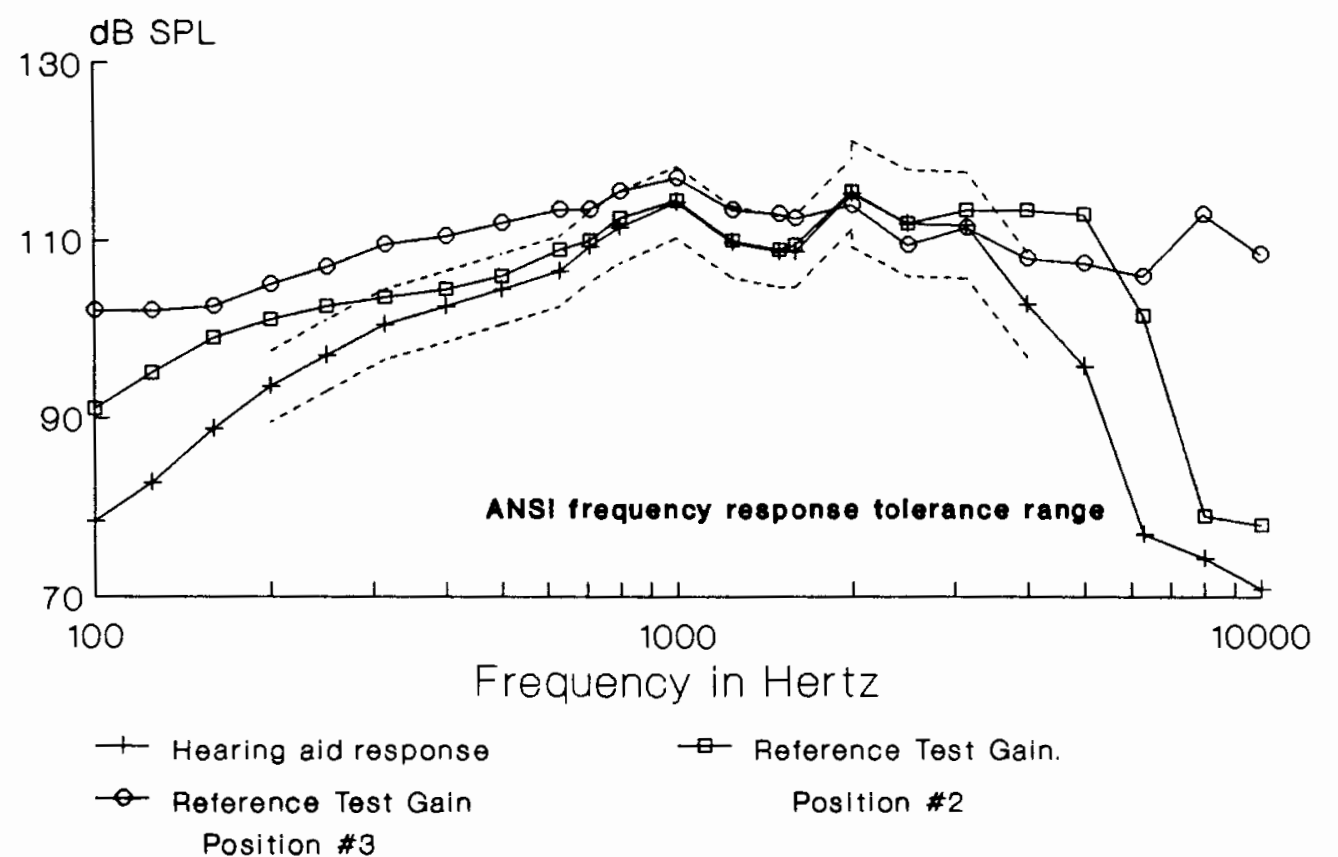

Telex 372 L-A coupled using Direct Audio Input to the Phonic Ear System 4. Input level set at 60 dB SPL. 


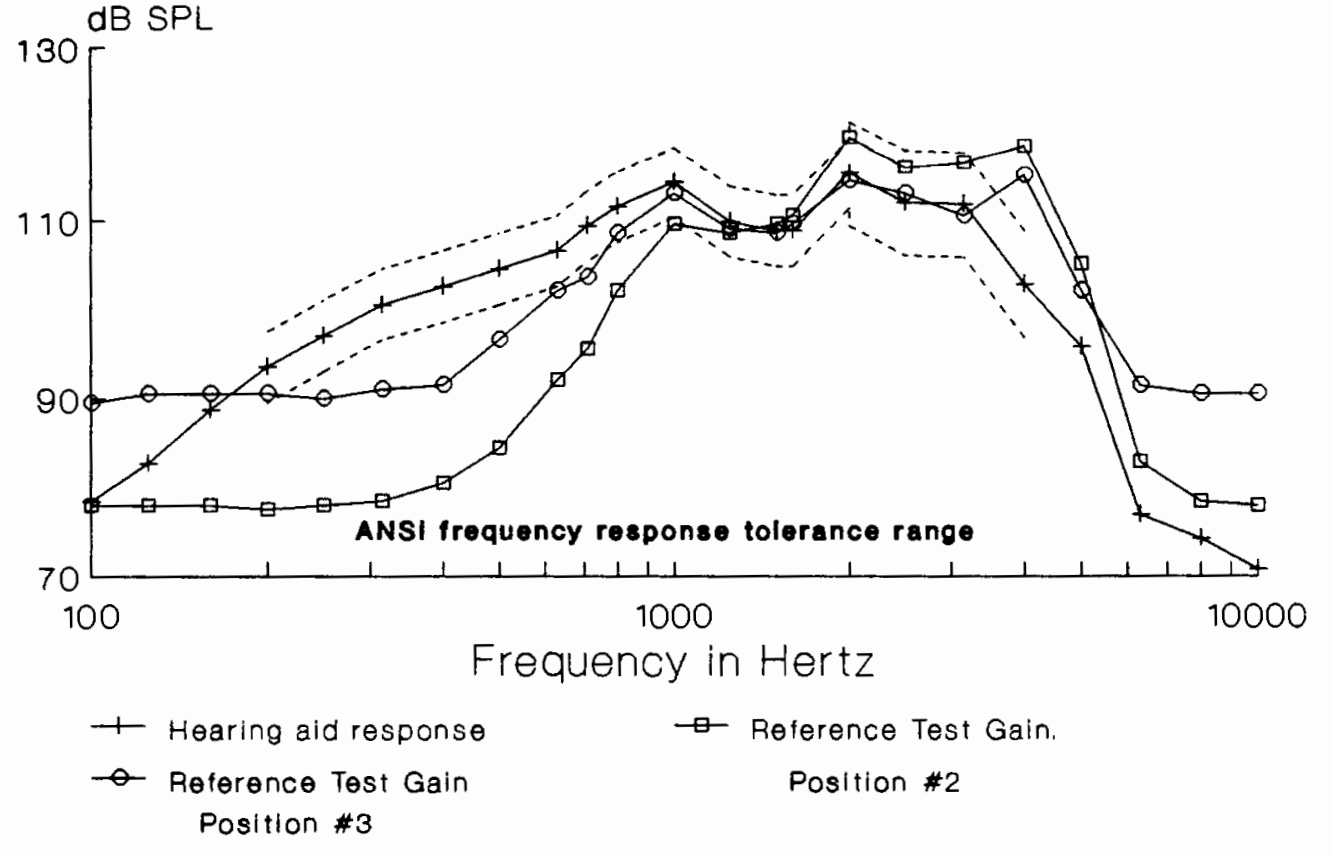

Telex 372 L-A coupled using Personal Mini-loop to the Telex TDR-4. Input level set at $60 \mathrm{~dB}$ SPL.

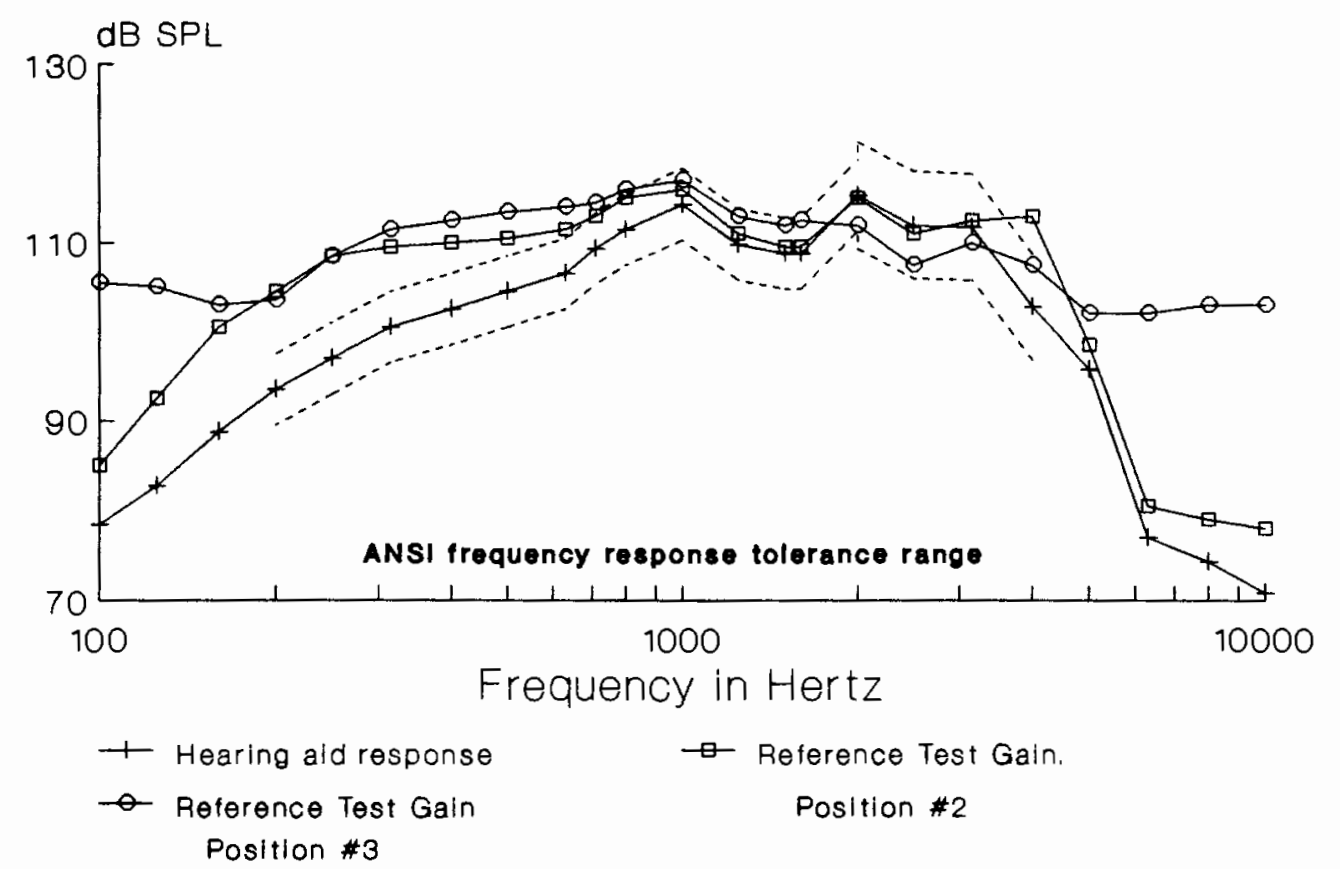

Telex 372 L-A coupled using Direct Audio Input to the Telex TDR-4. Input level set at $60 \mathrm{~dB}$ SPL. 


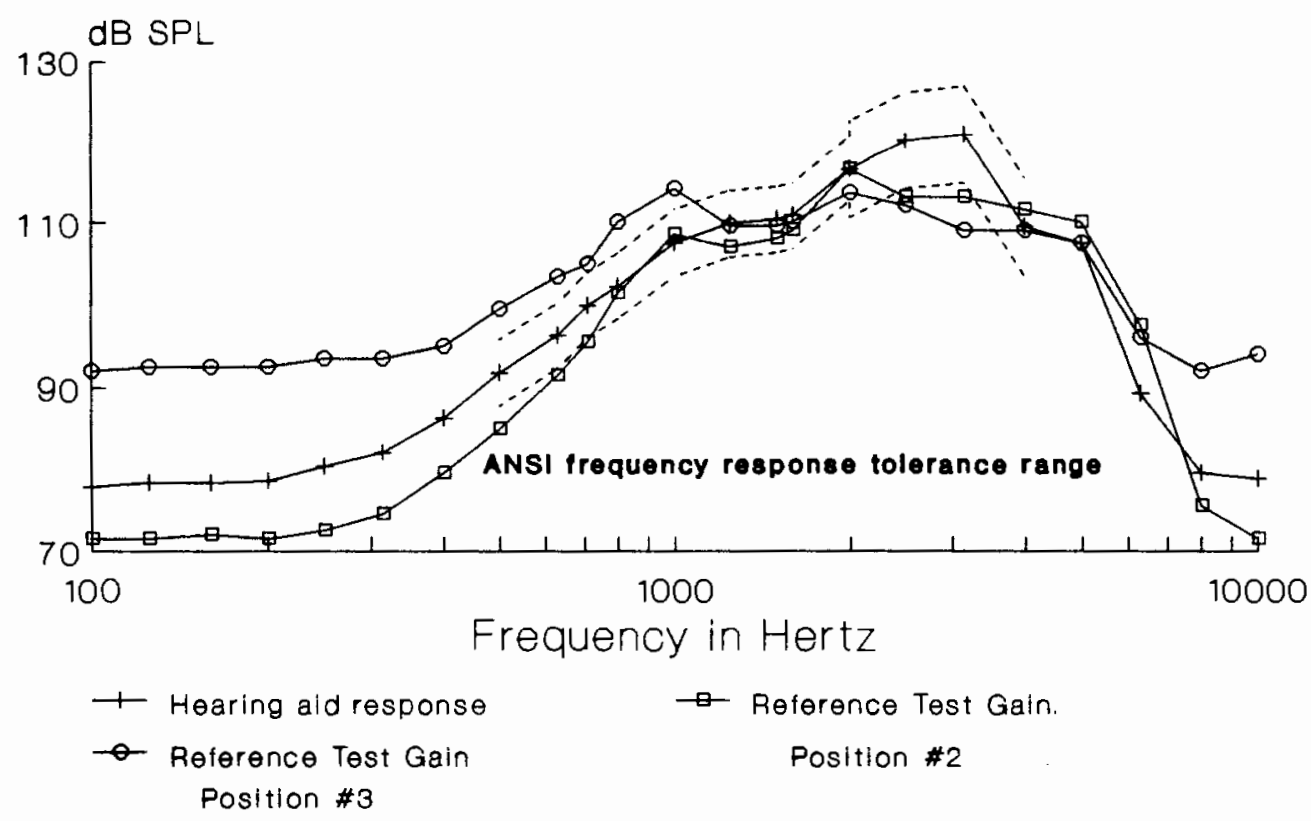

PE 600 PPCH-A coupled using Personal Mini-loop to the Comtek companion. Input level set at $60 \mathrm{~dB}$ SPL.

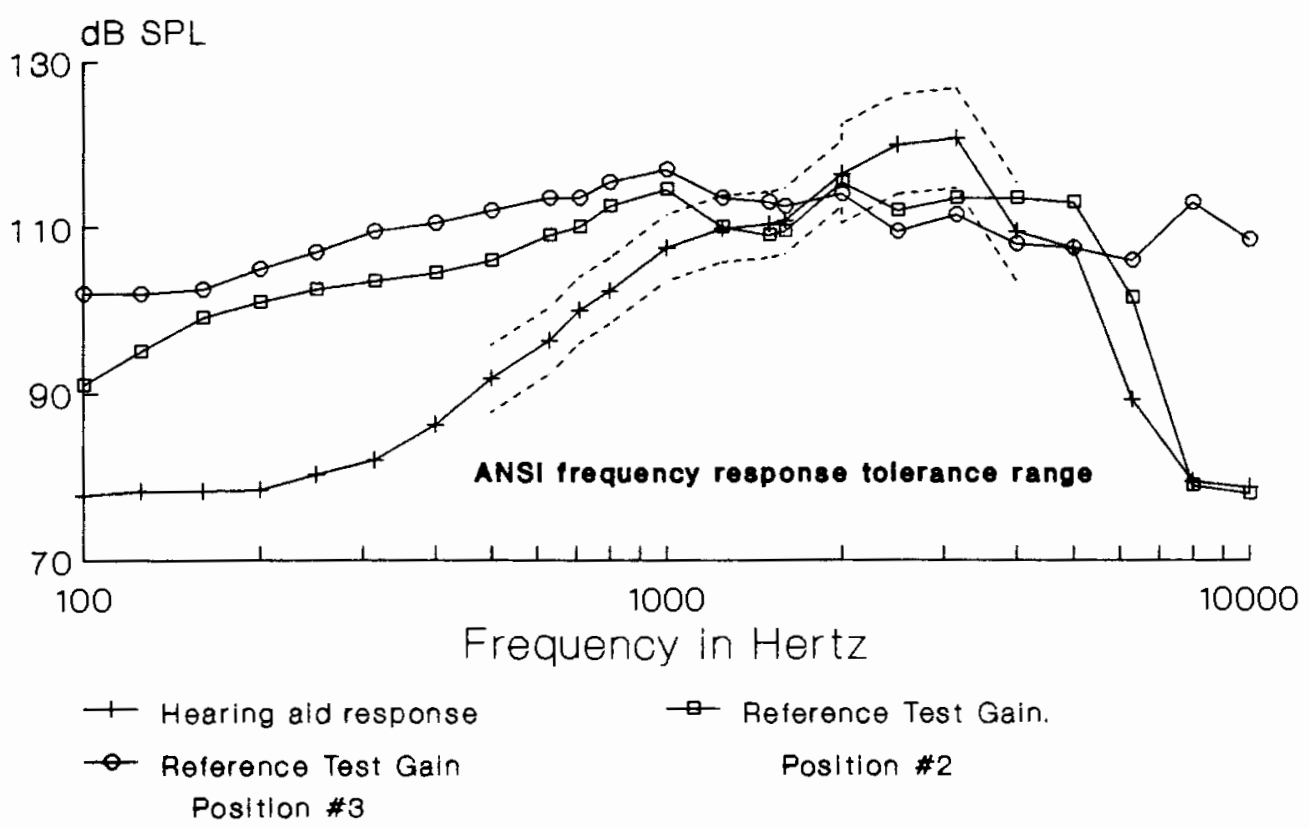

PE 600 PPCH-A coupled using Direct sudio Input to the Comtek companion. Input level set at $60 \mathrm{~dB}$ SPL. 


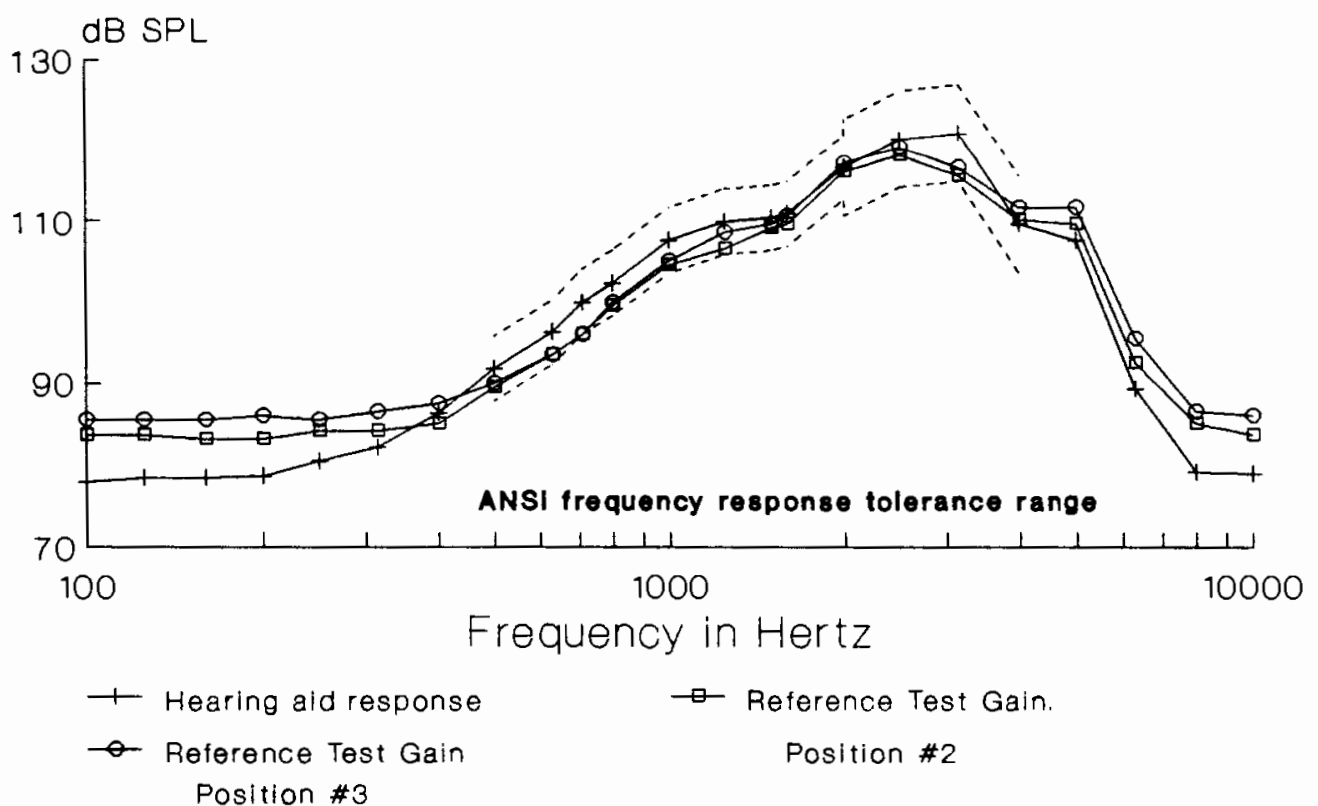

PE 600 PPCH-A coupled using Personal Mini-loop to the Phonic Ear System 4. Input level set at $60 \mathrm{~dB}$ SPL.

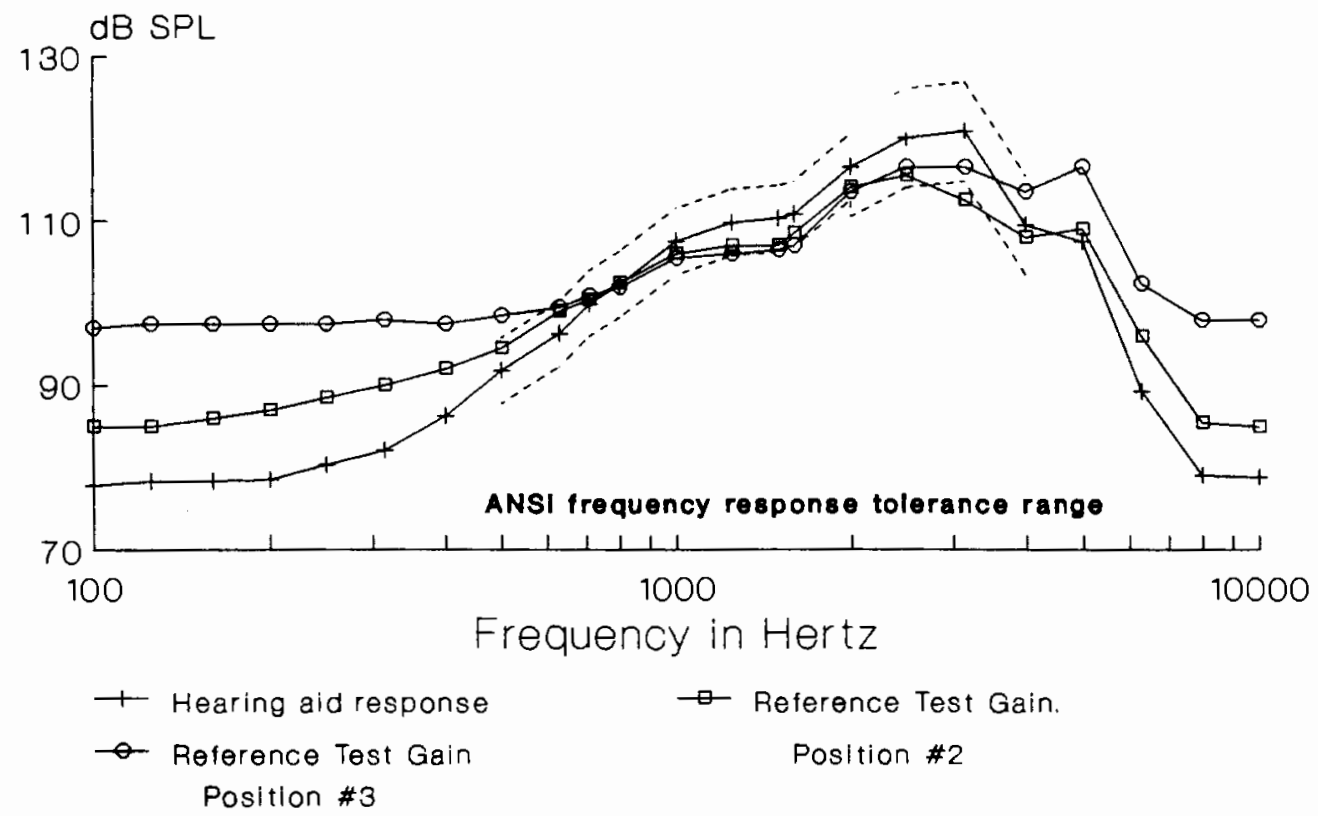

PE 600 PPCH-A coupled using Direct Audio Input to the Phonic Ear System 4. Input level set at $60 \mathrm{~dB}$ SPL. 
$130 \overbrace{}^{\mathrm{dB} S P L}$

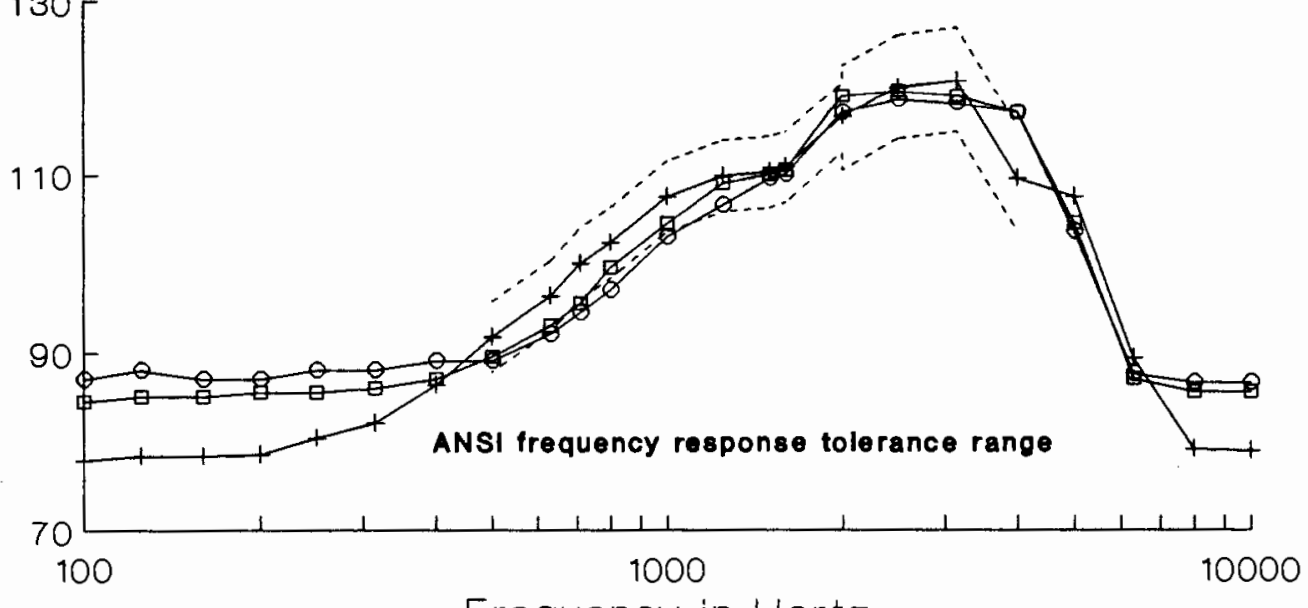

Frequency in Hertz

+ Hearing aid response

$\rightarrow$ Reference Test Gain.

$\rightarrow$ Reference Test Gain

Position \#2

Position \#3

PE 600 PPCH-A coupled using Personal Mini-loop to the Telex TDR-4. Input level set at 60 dB SPL.

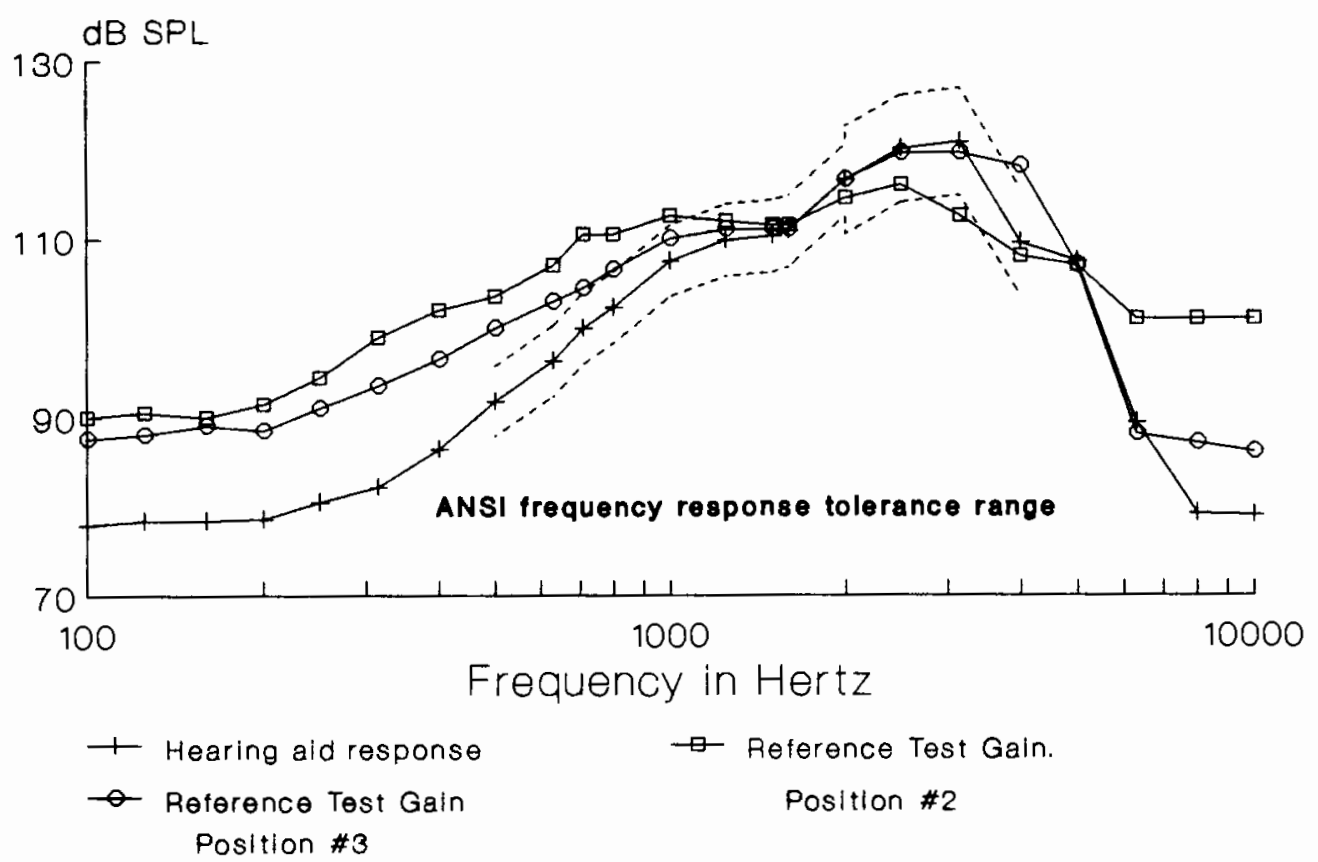

PE 600 PPCH-A coupled using Direct Audio Input to the Telex TDR-4. Input level set at 60 aB SPL. 


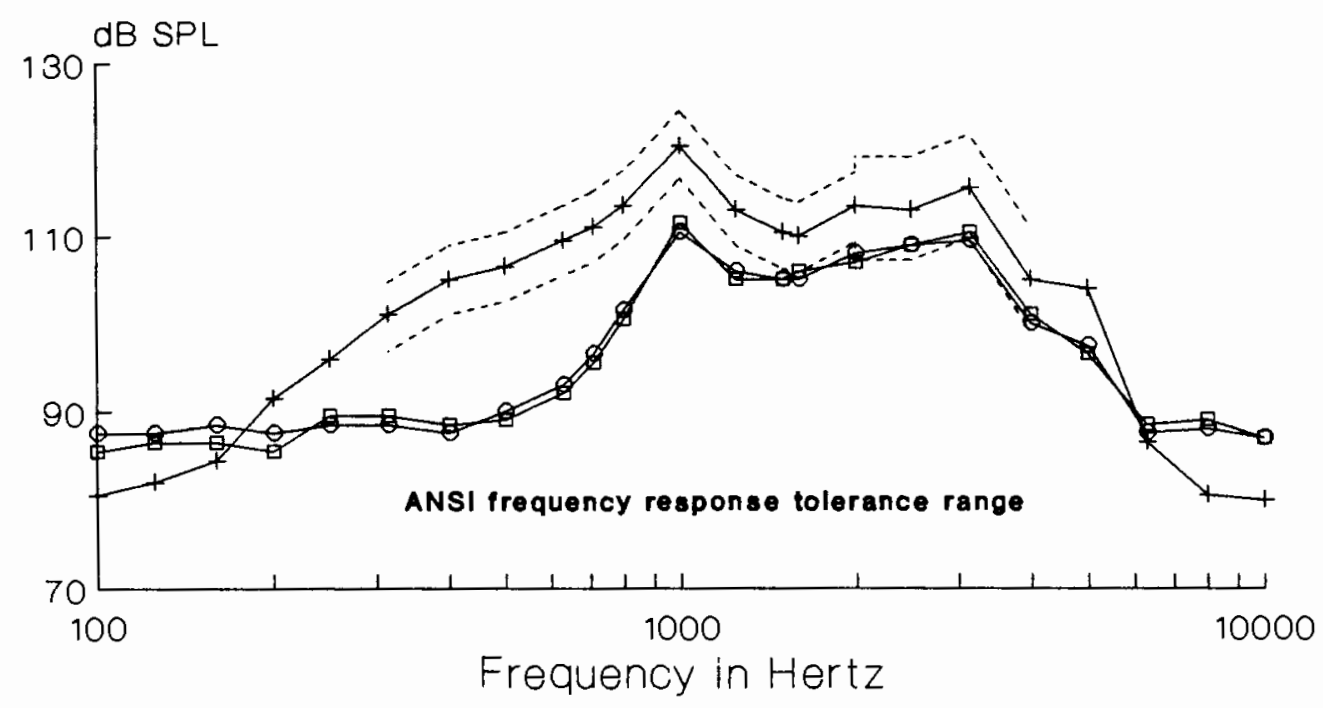
- Hearing ald response
$\rightarrow$ Reference Test Gain.
- Reference Test Gain
Position \#2
Position \#3

UE 12 PPCL-A coupled using Personal Mini-loop to the comtek Companion. Input level set at $60 \mathrm{~dB}$ SPL.

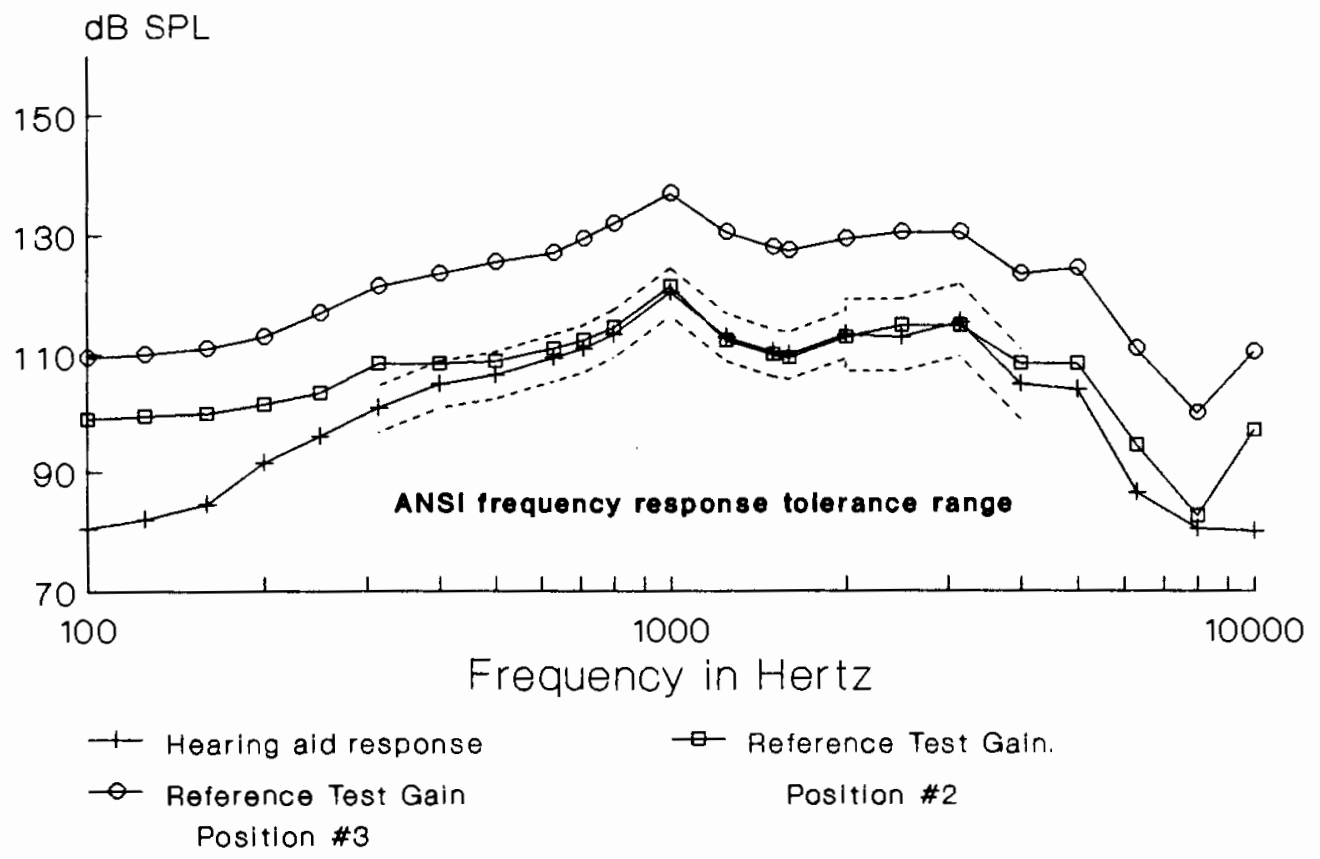

UE 12 PPCL-A coupled using Direct Audio Input to the Comtek Companion. Input level set at $60 \mathrm{~dB}$ SPL. 


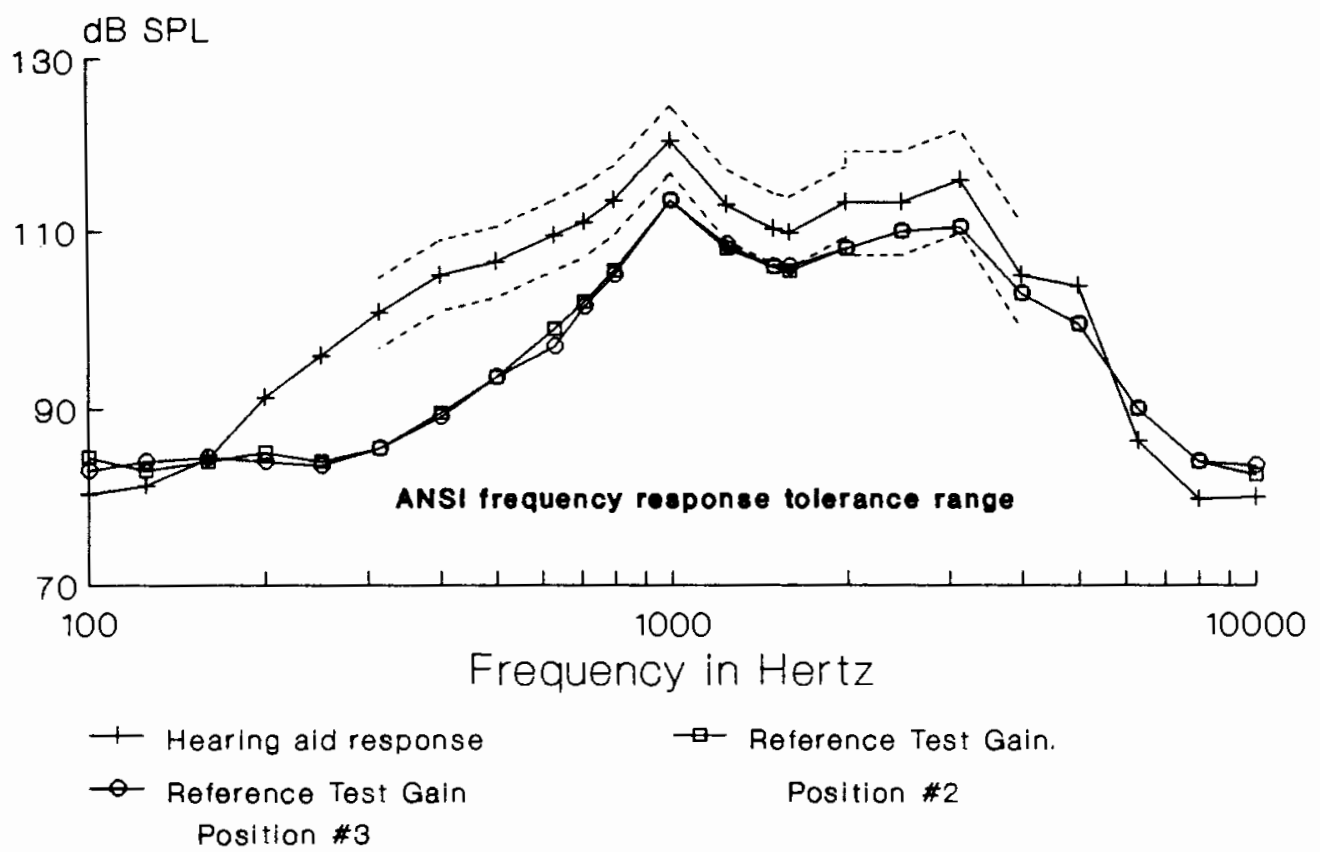

UE 12 PPCL-A coupled using Personal Mini-loop to the Phonic Ear System 4. Input level set at 60 dB SPL.

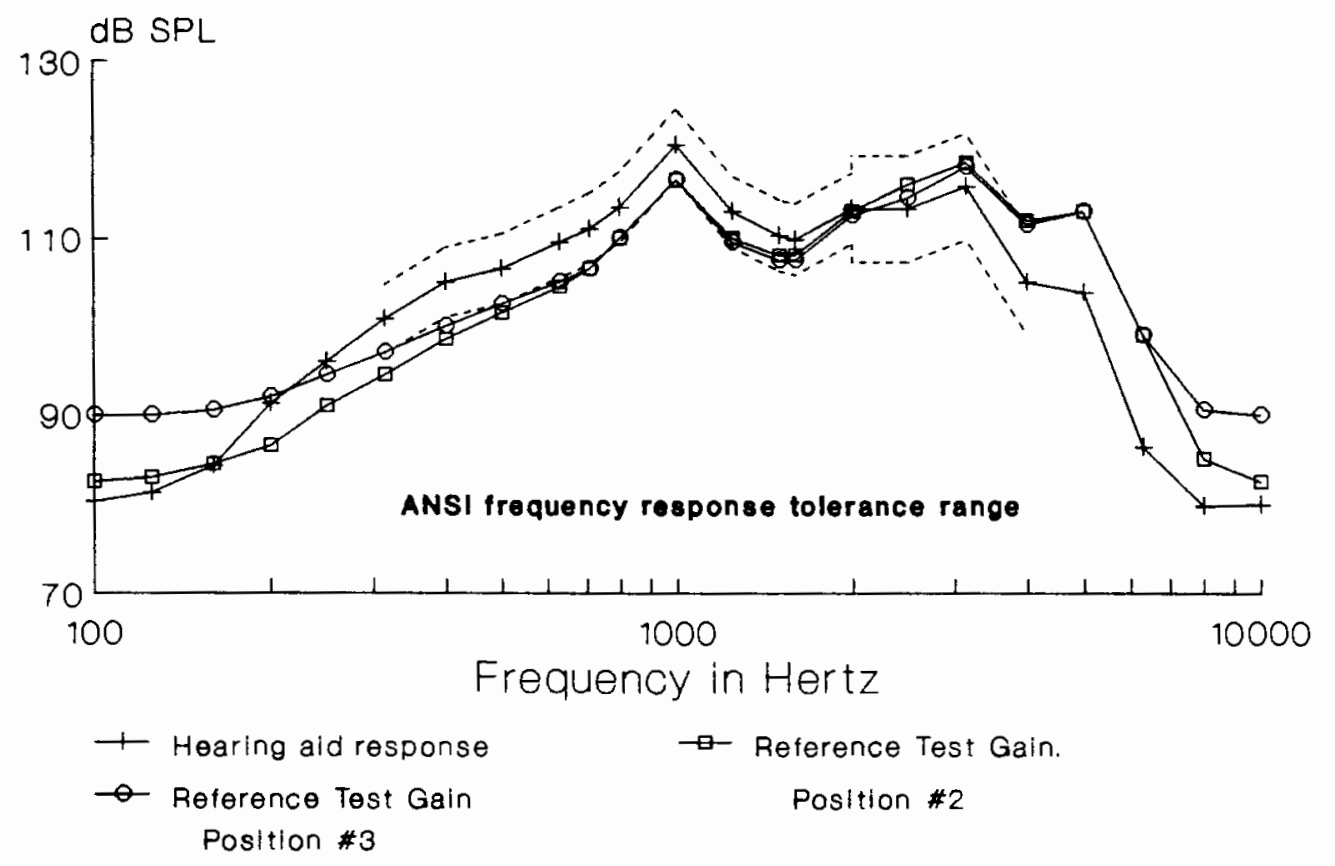

UE 12 PPCL-A coupled using Direct Audio Input to the Phonic Ear System 4. Input level set at $60 \mathrm{~dB}$ SPI. 


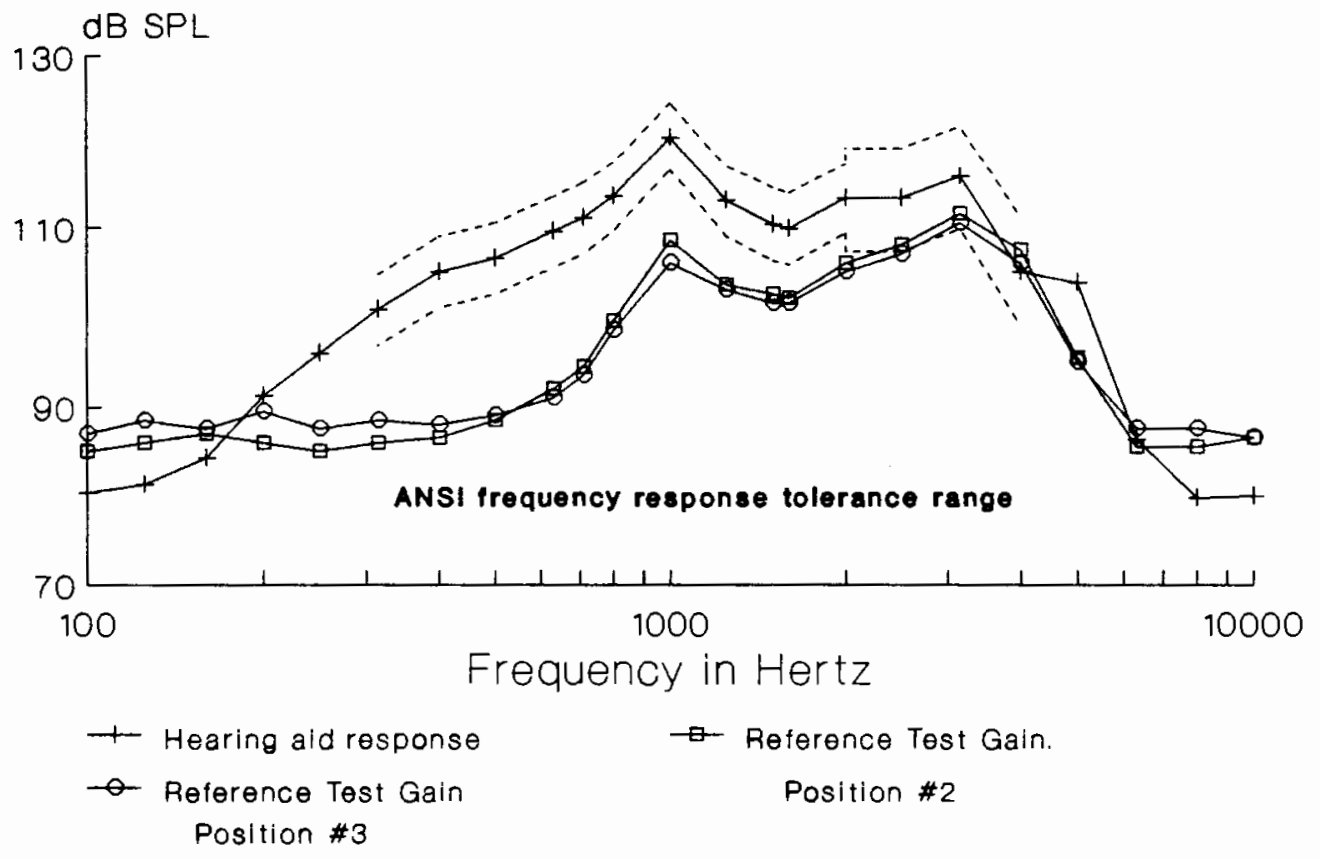

UE 12 PPCL-A coupled using Personal Mini-loop to the Telex TDR-4. Input level set at $60 \mathrm{~dB}$ SPL.

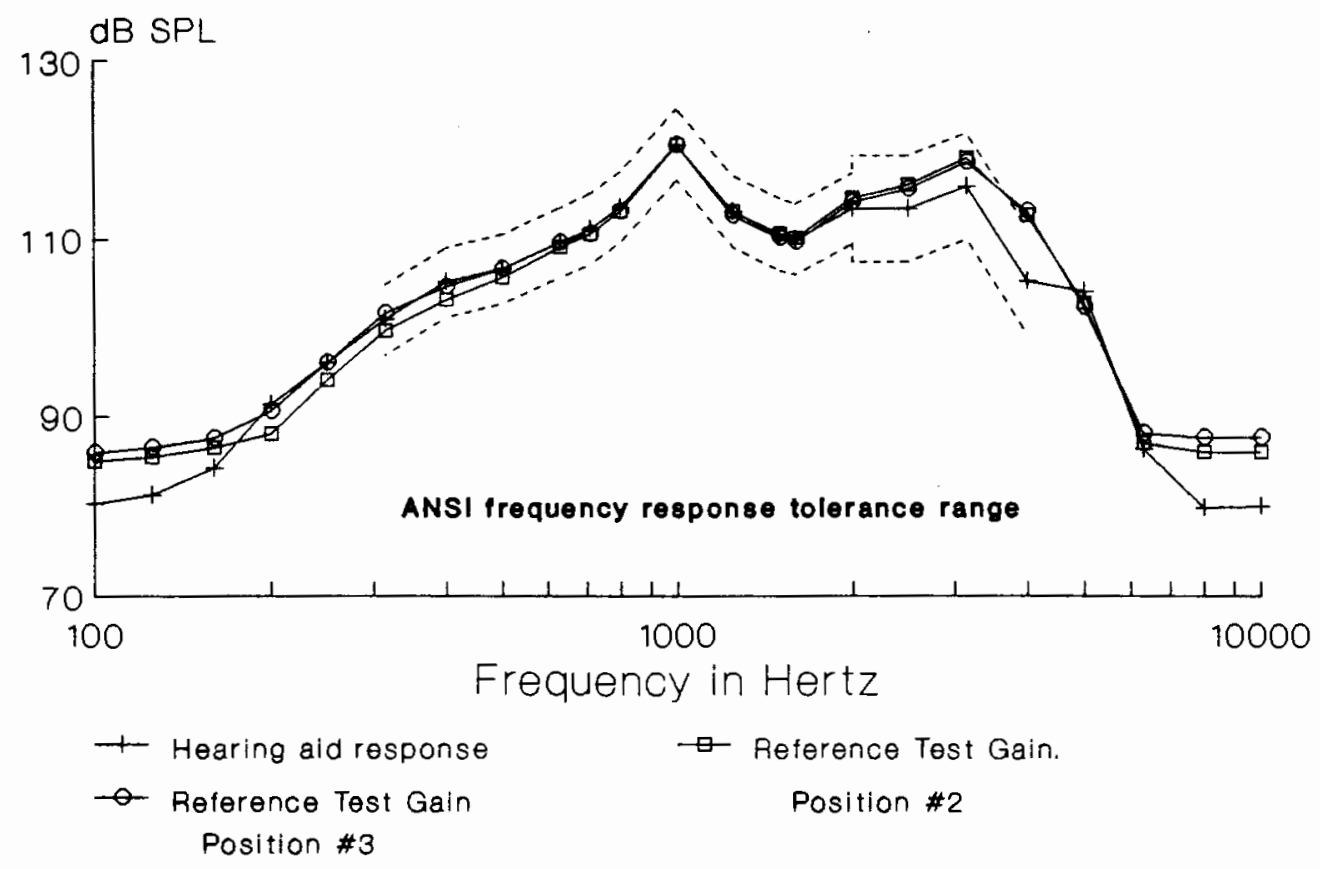

UE 12 PPCL-A coupled using Direct Audio Input to the Telex TDR-4. Input level set at $60 \mathrm{~dB}$ SPL. 
APPENDIX B

CODES FOR COMBINATIONS OF HEARING AIDS

AND FM AUDITORY TRAINERS AND

TEST CONDITIONS 
CODES FOR COMBINATIONS OF HEARING AIDS

AND FM AUDITORY TRAINERS AND

TEST CONDITIONS

\begin{tabular}{ccc}
\hline CODE & HEARING AID & FM AUDITORY TRAINER \\
\hline A & Telex 372 L-A & Comtek Companion \\
B & Telex 372 L-A & Phonic Ear System 4 \\
C & Telex 372 L-A & Telex TDR-4 \\
D & PE 600 PPCH-A & Comtek Companion \\
E & PE 600 PPCH-A & Phonic Ear System 4 \\
F & PE 600 PPCH-A & Telex TDR-4 \\
G & UE 12 PPCL-A & Comtek Companion \\
H & UE 12 PPCL-A & Phonic Ear System 4 \\
I & UE 12 PPCL-A & Telex TDR-4 \\
\hline
\end{tabular}

SUMMARY OF TEST

CONDITIONS

\begin{tabular}{|c|c|c|c|}
\hline Test & $\begin{array}{l}\text { Condition } \\
\text { No. }\end{array}$ & Coupling Method & $\begin{array}{l}\text { Volume Control } \\
\text { Setting }\end{array}$ \\
\hline & \#1 & $\begin{array}{l}\text { Personal } \\
\text { Mini-loop }\end{array}$ & $\begin{array}{l}\text { Reference Test } \\
\text { Gain Position } \# 2\end{array}$ \\
\hline & $\# 2$ & $\begin{array}{l}\text { Personal } \\
\text { Mini-loop }\end{array}$ & $\begin{array}{l}\text { Reference Test } \\
\text { Gain Position \#3 }\end{array}$ \\
\hline & $\# 3$ & $\begin{array}{l}\text { Direct } \\
\text { Audio Input }\end{array}$ & $\begin{array}{l}\text { Reference Test } \\
\text { Gain Position } \# 2\end{array}$ \\
\hline & $\# 4$ & $\begin{array}{l}\text { Direct } \\
\text { Audio Input }\end{array}$ & $\begin{array}{l}\text { Reference Test } \\
\text { Gain Position \#3 }\end{array}$ \\
\hline
\end{tabular}


The following is a listing of the different volume control settings used for each of the Reference Test Gain Positions.

Reference Test Gain Position \#1. This was the control frequency response of the hearing aid tested alone. The hearing aid volume control was adjusted so that the high frequency average of $1,1.6$, and $2.5 \mathrm{kHz}$ with a $60 \mathrm{~dB}$ SPL input equaled the high frequency average minus $17 \pm 1 \mathrm{~dB}$ SPL with a $90 \mathrm{~dB}$ SPL input.

Reference Test Gain Position \#2. The FM auditory trainer volume control was set to full-on gain, and the hearing aid volume control was adjusted to meet the same criteria above.

Reference Test Gain Position \#3. The hearing aid volume control was set to full-on gain, and the FM auditory trainer volume control was adjusted to meet the same criteria as above. 
APPENDIX C

THE TOLERANCE METHOD FOR THE FREQUENCY RESPONSE CURVE OF HEARING AIDS (ANSI S3.22 1982

$$
6.10 .1,6.10 .2)
$$


A tolerance template, composed of the upper and lower limits of variation in frequency response curve values allowed by ANSI S3.22 (1982) standards was superimposed on the hearing aid microphone response curves. These limits are determined by calculating the average of the 1000,1600 , and $2500 \mathrm{~Hz}$ response levels, then $20 \mathrm{~dB}$ was subtracted from this average and a line was drawn parallel to the abscissa at this level. The lowest frequency at which this line intersects the frequency response curve is $f_{1}$, the highest frequency where they intersect is $f_{2}$, with $f_{2}$ not exceeding $5000 \mathrm{~Hz}$. The frequency response curve is separated into a high and a low band. The frequency range for the low band extends from $1.25 \times f_{1}$ to $2000 \mathrm{~Hz}$ with a range of variation of $\pm 4 \mathrm{~dB}$ of the manufacturer's specifications for that model. The high band extends from $2000 \mathrm{~Hz}$ to $0.8 \times \mathrm{f}_{2}$ or $4000 \mathrm{~Hz}$, whichever is lower. Within this band the frequency response curve must fall within $\pm 6 \mathrm{~dB}$ of the manufacturer's specifications for that model.

The hearing aid-alone frequency response was measured three times. Since there was a mean difference of $-1.53 \mathrm{~dB}$ between these three frequency response curves, the two 
curves which were closest in agreement with each other were averaged at each individual frequency. This mean frequency response was used to generate the tolerance ranges for each of the three hearing aids. The tolerance ranges were computed from this data to control for variation from the manufacturers' specifications. The mean difference between the best two curves for all three hearing aids was $-1.1 \mathrm{~dB}$. In addition, adjustments of the tolerance template are also allowed. This is to accommodate small changes in a frequency response curve which would otherwise make it fail to meet this standard. The template must remain square with the grid of the curve being measured, but any amount of vertical adjustment as well as horizontal adjustments of up to $\pm 10 \%$ in frequency are allowed according to ANSI S3.22 (1982) standards. These were the criteria used to determine whether the combined response of the hearing aid and FM auditory trainer under one of the experimental conditions fell within the acceptable range of variation for frequency response as compared to the hearing aid microphone response. These criteria allowed precise determination of the frequencies and number of decibels where any given combination under any test condition exceeded these limits. In addition to the strict tolerance approach outlined above, the interaction of the independent variables on the dependent variable, in this case frequency response, was examined. The objective was to investigate the interaction 
of the test conditions with the hearing aids, the test conditions with the FM systems, and the hearing aids with the FM systems. There were four test conditions. Test Conditions \#1 and \#2 used the Personal Mini-loop, and \#3 and \#4 used Direct Audio Input. With each input mode two reference test gain positions were determined, first by setting the FM receiver at full-on gain and adjusting the hearing aid volume control, and second by setting the hearing aid at full-on gain and adjusting the FM receiver volume control. SSPL9o curves of the combined units were only used to calculate the SSPL90 high frequency average in order to obtain Reference Test Gain Positions \#2 or \#3, therefore, this data was not analyzed. 